NBER WORKING PAPER SERIES

\title{
MONEY, INTEREST RATES, AND EXCHANGE RATES WITH ENDOGENOUSLY SEGMENTED ASSET MARKETS
}

\author{
Fernando Alvarez \\ Andrew Atkeson \\ Patrick J. Kehoe \\ Working Paper 7871 \\ http://www.nber.org/papers/w7871 \\ NATIONAL BUREAU OF ECONOMIC RESEARCH \\ 1050 Massachusetts Avenue \\ Cambridge, MA 02138 \\ September 2000
}

We thank Robert E. Lucas, Jr., Dean Corbae, and Stanley Zin for their comments and the National Science Foundation for its support. The views expressed herein are those of the authors and not necessarily those of the Federal Reserve Bank of Minneapolis, the Federal Reserve System, or the National Bureau of Economic Research.

(C) 2000 by Fernando Alvarez, Andrew Atkeson, and Patrick J. Kehoe. All rights reserved. Short sections of text, not to exceed two paragraphs, may be quoted without explicit permission provided that full credit, including (C) notice, is given to the source. 
Money, Interest Rates, and Exchange Rates with Endogenously Segmented Asset Markets

Fernando Alvarez, Andrew Atkeson, and Patrick J. Kehoe

NBER Working Paper No. 7871

September 2000

\begin{abstract}
This paper analyzes the effects of money injections on interest rates and exchange rates in a model in which agents must pay a Baumol-Tobin style fixed cost to exchange bonds and money. Asset markets are endogenously segmented because this fixed cost leads agents to trade bonds and money only infrequently. When the government injects money through an open market operation, only those agents that are currently trading absorb these injections. Through their impact on these agents' consumption, these money injections affect real interest rates and real exchange rates. We show that the model generates the observed negative relation between expected inflation and real interest rates. With moderate amounts of segmentation, the model also generates other observed features of the data: persistent liquidity effects in interest rates and volatile and persistent exchange rates. A standard model with no fixed costs can produce none of these features.
\end{abstract}

Fernando Alvarez

Department of Economics

University of Chicago

1126 East $59^{\text {th }}$ Street

Social Science Building, Room 442

Chicago, IL 60637

and Universidad Di Tella, and NBER

f-alvarezl@uchicago.edu

Patrick J. Kehoe

Federal Reserve Bank of Minneapolis

90 Hennepin Avenue

P.O. box 291

Minneapolis, MN 55480

and University of Minnesota

and NBER

pkehoe@res.mpls.frb.fed.us
Andrew Atkeson

3141 Highland Pland NW

Washington, DC 20008

and Federal Reserve Bank of Minneapolis, University of Minnesota, and the NBER andy@atkeson.net 
Several features of the observed relationships between money and both interest rates and exchange rates are difficult to account for in standard monetary models. Motivated by the work of Baumol (1952) and Tobin (1956), some economists have argued that adding frictions which lead to a segmented market for trading money and interest-bearing assets might help improve these models. (See Grossman and Weiss 1983, Rotemberg 1984, 1985, and Lucas 1990, among others.) Here we build on this literature by developing a model with endogenously segmented asset markets. Our model is both simple and promising as a way to account for the data.

In our model, agents must pay a fixed cost to transfer money between the asset market and the goods market. This fixed cost leads agents to trade bonds and money only infrequently. In any given period, only a fraction of agents are actively trading; that is, the asset market is segmented. When the government injects money through an open market operation, then, only the currently active agents are on the other side of the transaction, and only their marginal utilities determine interest rates and exchange rates. Money injections are absorbed exclusively by these active agents: the injections increase the agents' current consumption; hence, real interest rates fall and the real exchange rate depreciates. We refer to this effect of money injections on real interest rates and real exchange rates as the segmentation effect.

Our main contribution here is to derive with pencil and paper the implications of segmented asset markets for the relationships of money, interest rates, and exchange rates for stochastic processes for shocks motivated by the data. Our derivation sheds light on how the complicated relationships between money, interest rates, and exchanges rates are all driven by a simpler one, namely, that between money injections and the marginal utility of active agents. We also show that some predictions of a simple, quantitative version of our model come close to matching features of the data which standard models without segmentation have not been able to produce.

Two features of interest rates have been discussed extensively in the literature. First, expected inflation and real interest rates generally move in opposite directions. This has been documented by Barr and Campbell (1997) using indexed and nominal bonds. (See also Pennacchi 1991 and Campbell and Ammer 1993.) Second, at least since Friedman (1968), open market operations have been thought to have liquidity effects: money injections lead initially to a decline in short-term nominal interest rates, a decline which is thought to decay over time, with shortterm rates eventually rising to normal levels or higher. Accordingly, money injections are thought to steepen the yield curve, lowering long-term rates less than short-term rates, or even to twist 
the yield curve by raising long-term rates. The vector autoregression (VAR) literature has been somewhat successful in confirming this pattern in the data. (See Cochrane 1994 and Christiano, Eichenbaum, and Evans 1998.)

Our model with segmented asset markets can produce both of these features while a standard model cannot. In a standard model without market segmentation, persistent money injections increase expected inflation but have no effects on real interest rates, so the model induces no relation between them. In addition, these injections raise nominal interest rates of all maturities and flatten or even invert the yield curve. In our model, however, money injections move expected inflation and real interest rates in opposite directions. These injections thus generate the negative correlation between expected inflation and real interest rates that is observed in the data. Also, if asset markets are sufficiently segmented, money injections in our model have liquidity effects: money injections lower short-term nominal interest rates and steepen or even twist the yield curve by lowering short rates and raising long ones. We show that with moderate amounts of segmentation, our model can produce dynamic responses similar to those found in the VAR literature. (Moreover, our model generates persistent real effects from market segmentation even from anticipated shocks. Cochrane (1998) argues that a reasonable interpretation of the VAR results may require models with this property.)

After our look at money and interest rates, we turn to some prominent features of money and exchange rates. These features are different for countries with different rates of inflation. For low inflation countries, real and nominal exchange rates have similar variability, they are highly correlated, and both are persistent. For high inflation countries, real exchange rates are much less volatile than nominal exchange rates.

A standard model can produce none of these features, but our endogenously segmented model can produce them all. In a standard model, money injections do not affect real exchange rates, and they affect nominal exchange rates only through their impact on inflation. In our model, in contrast, when inflation is low, asset markets are segmented and money injections have a substantial impact on real exchange rates. With moderate amounts of segmentation, therefore, real and nominal exchange rates have similar variability, they are highly correlated, and both are persistent, just as in the data. When inflation is high, agents trade more frequently, markets become less segmented, and money injections have a smaller impact on real exchange rates. Hence, in our model as in the data on high inflation countries, real exchange rates are significantly less 
volatile than nominal exchange rates.

Our model with segmented markets is a standard cash-in-advance model with the addition of fixed costs for agents to exchange money and bonds. In our model, the household begins each period with some cash in the goods market and then splits into a worker and a shopper. The worker sells the current endowment for cash, and the shopper decides either to buy goods with just the current real balances or to pay the fixed cost to transfer cash to or from the asset market and then buy goods. The household's endowment and, thus, the household's cash holdings are random and idiosyncratic.

The shopper follows a cutoff rule that define zones of activity and inactivity for trading cash and interest-bearing assets. In the zone of activity, shoppers with high real balances pay a fixed cost to transfer cash to the asset market, while shoppers with low real balances pay a fixed cost to obtain cash from the asset market. Shoppers with intermediate real balances are in the zone of inactivity. They do not pay a fixed cost; they simply spend their current real balances. Over time, households stochastically cycle through the zones of activity and inactivity as their idiosyncratic shocks vary. If the fixed cost is zero, all agents are active, and the model reduces to the standard one of Lucas (1984).

When discussing exchange rates, we abstract from trade in goods across countries in order to focus on the role of asset market segmentation. By so doing, we follow the spirit of Lucas (1978) in using marginal rates of substitution to price assets even though there is no trade in equilibrium.

There is a large literature in this general area. Our paper is clearly related to the work of Baumol (1952) and Tobin (1956). More recently, Jovanovic (1982), Romer (1986), and Chatterjee and Corbae (1992) have developed general equilibrium versions of Baumol's and Tobin's models and have used their versions to study how different constant inflation rates affect the steady state. ${ }^{1}$ In contrast to these studies, however, ours examines the dynamic responses of interest rates and exchange rates to money growth shocks.

Grossman and Weiss $(1983)$ and Rotemberg $(1984,1985)$ study the dynamic responses of interest rates and exchange rates in deterministic models with exogenous segmentation. In addition to this segmentation, the Grossman-Weiss-Rotemberg models also exogenously limit asset trade to uncontingent bonds. Because of that market incompleteness, these models have - besides the pure liquidity effects from the trading frictions-complicated wealth effects which effectively limit these studies to onetime unanticipated shocks in deterministic environments. Grossman (1987) 
extends this work to include proportional costs of trading money and assets and, hence, endogenous segmentation, but because of the market incompleteness, his work is also limited to onetime unanticipated shocks in deterministic environments.

We go beyond this literature by analyzing a fully stochastic model with shocks motivated by the processes in the data. Such a step is clearly required to develop the empirical implications of market segmentation. We take this step by drawing on a device of Lucas (1990) that lets us abstract from wealth effects. Lucas (1990) organizes agents into coalitions in which agents pool their resources and choose consumption subject to a single budget constraint for the coalition as a whole, subject to restrictions on the trading technology. Given the trading technology, then, markets are complete. Thus, money injections have real effects only because of the trading frictions and not because of additional exogenous market incompleteness. We follow Lucas (1990) and allow agents to trade a complete set of state-contingent bonds in the asset market in order to eliminate complicated but inessential wealth effects.

We differ from Lucas (1990) in terms of both the trading friction used and the results obtained. Lucas assumes that the coalition must divide its cash each period into one portion to be used to purchase goods and another portion to be traded for bonds in the asset market before the size of the current open market operation is announced. Unfortunately, in that model, only unexpected money shocks have real effects. Hence, the model cannot produce the Barr and Campbell (1997) observations on expected inflation and real interest rates. Moreover, in that model, liquidity effects last only one period. Fuerst (1992) and Christiano and Eichenbaum (1995) extend Lucas' (1990) model to include production, and they get similar results. Grilli and Roubini (1992) and Schlagenhauf and Wrase (1995a) extend this work to the open economy. They also find that the response of real exchange rates to money injections lasts only one period. In related work, Alvarez and Atkeson (1997) use coalitions to extend the work of Rotemberg (1985), but with this friction, markets can be highly segmented only if velocity is extremely low.

In an extension of their basic model, Christiano and Eichenbaum (1992) and Chari, Christiano, and Eichenbaum (1995) add quadratic costs of adjusting the portfolio between periods to the infinite adjustment costs within the period. They show that this setup can generate persistent liquidity effects. Evans and Marshall (1998) use that extended model to analyze the responses of interest rates of different maturities to money shocks. Dotsey and Ireland (1995) and Schlagenhauf and Wrase (1995b) criticize the lack of symmetry in such a model between the adjustment 
costs within a period and across periods. Dotsey and Ireland (1995) show that when a model has quadratic costs of adjustment both within and across periods, the liquidity effects are small.

In contrast to the trading frictions in the literature initiated by Lucas (1990), our trading frictions are close to those of the Baumol-Tobin models. These frictions can generate the Barr and Campbell (1997) observations and persistent liquidity effects even though costs are symmetric. Moreover, in our study, all the results can be derived with paper and pencil, so that the essential driving forces in the model are easily seen.

\section{A One-Country Economy}

First we sketch the basic outline of our model economy, and then we fill in the details.

\section{A. The Outline}

We begin with a one-country cash-in-advance economy with an infinite number of time periods $t=0,1,2, \ldots$, a government, and a continuum of households of measure 1 . Trade in this economy occurs in two separate locations: an asset market and a goods market. In the asset market, households trade cash and bonds which promise delivery of cash in the asset market in the next period, and the government introduces cash in the asset market via open market operations. In the goods market, households use cash to buy goods subject to a cash-in-advance constraint, and households sell their endowments of goods for cash. Households face a real fixed cost of $\gamma$ for each transfer of cash between the asset market and the goods market. Except for this fixed cost, the model is a standard cash-in-advance model like Lucas' (1984).

This economy has two sources of uncertainty: idiosyncratic shocks to households' endowments and shocks to money growth. The timing within each period $t \geq 1$ is illustrated in Figure 1. We emphasize the physical separation between markets by placing the asset market in the top half of the figure and the goods market in the bottom half. Households enter the period with the cash $P_{-1} y_{-1}$ they obtained from selling their endowments at $t-1$, where $P_{-1}$ is the price level and $y_{-1}$ is their idiosyncratic random endowment at $t-1$. The government conducts an open market operation in the asset market, which determines the realization of money growth $\mu$ and the current price level $P$.

Each household then splits into a worker and a shopper. The worker sells the household endowment $y$ for cash $P y$ and rejoins the shopper at the end of the period. The shopper takes

the household's cash $P_{-1} y_{-1}$ with real value $m=P_{-1} y_{-1} / P$ and shops for goods. The shopper 
can choose to pay the fixed cost $\gamma$ to transfer cash $P x$. with real value $x$ to or from the asset market. This fixed cost is paid in cash obtained in the asset market. If the shopper pays the fixed cost, then the cash-in-advance constraint is $c=m+x$, where $c$ is consumption; otherwise, this constraint is $c=m$.

Each household also enters the period with bonds that are claims to cash in the asset market with payoffs contingent on both the household's idiosyncratic endowment $y_{-1}$ and the rate of money growth $\mu$ in the current period. This cash either can be reinvested in the asset market or, if the fixed cost is paid, can be transferred to the goods market. In addition, if the fixed cost is paid, then cash from the goods market can be transferred to the asset market and used to buy new bonds. In Figure 1, the asset market constraint is $B=\int q B^{\prime}+P(x+\gamma)$ if the fixed cost is paid and $B=\int q B^{\prime}$ otherwise, where $B$ denotes the current realization of the state-contingent bonds and $\int q B^{\prime}$ the household's purchases of new bonds. At the beginning of the next period, period $t+1$, this household starts with cash $P y$ in the goods market and contingent bonds $B^{\prime}$ in the asset market.

In equilibrium, some households choose to pay the fixed cost to transfer cash between the goods and asset markets while others do not. We refer to households that pay the fixed cost as active and households that do not as inactive. Households with either sufficiently low real balances or sufficiently high real balances are active. Households with low real balances transfer cash from the asset market to the goods market while those with high real balances transfer cash in the opposite direction. Households with intermediate levels of real balances are in a zone of inactivity and simply consume their current real balances.

In Figure 1 and the body of the paper, we assume that the shopper's cash-in-advance constraint binds and that in the asset market households hold their assets in interest-bearing securities rather than in cash. In Appendix A, we provide sufficient conditions for this assumption to hold.

\section{B. The Details}

Now we flesh out the outline of this economy.

Each household's endowment $y$ is independent and identically distributed (i.i.d.) across households and across time with distribution $F$, which has density $f$. Let $Y=\int y f(y) d y$ be the constant aggregate endowment. Let $y^{t}=\left(y_{0}, \ldots, y_{t}\right)$ denote a typical history of individual shocks to endowments up through period $t$ and $f\left(y^{t}\right)=f\left(y_{0}\right) f\left(y_{1}\right) \ldots f\left(y_{t}\right)$ the probability density over such histories. Let $M_{t}$ denote the aggregate stock of money in period $t$ and $\mu_{t}=M_{t} / M_{t-1}$ the 
growth rate of that money supply. Let $\mu^{t}=\left(\mu_{1}, \ldots, \mu_{t}\right)$ denote the history of money growth shocks up through period $t$ and $g\left(\mu^{t}\right)$ the probability density over such histories.

To make all households identical in period 0 , we need to choose the initial conditions carefully. In period 0 , households have $\bar{B}$ units of government debt, which is a claim on $\bar{B}$ dollars in the asset market in period 0 . In this period, households trade only in bonds, not in goods. In period 1, households also have $y_{0} / \mu_{1}$ real balances in the goods market, where $y_{0}$ also has distribution $F$ and $\mu_{1}$ is the money growth shock at the beginning of period 1 .

The government issues one-period bonds with payoffs contingent on the aggregate state $\mu^{t}$. In period $t$, given state $\mu^{t}$, the government pays off outstanding bonds $B\left(\mu^{t}\right)$ in cash and issues claims to cash in the next asset market of the form $B\left(\mu^{t}, \mu_{t+1}\right)$ at prices $q=\left(\mu^{t}, \mu_{t+1}\right)$. The government budget constraint in period $t \geq 1$, given state $\mu^{t}$, is

$$
B\left(\mu^{t}\right)=M\left(\mu^{t}\right)-M\left(\mu^{t-1}\right)+\int_{\mu_{t+1}} q\left(\mu^{t}, \mu_{t+1}\right) B\left(\mu^{t}, \mu_{t+1}\right) d \mu_{t+1}
$$

In period 0 , this constraint is $\vec{B}=\int_{\mu_{1}} q\left(\mu_{1}\right) B\left(\mu_{1}\right) d \mu_{1}$.

In the asset market in each period and state, households trade a complete set of one-period bonds that have payoffs next period which are contingent on both the aggregate event $\mu_{t+1}$ and the household's endowment realization $y_{t}$. A household in period $t$ with aggregate state $\mu^{t}$ and individual shock history $y^{t-1}$ purchases $B\left(\mu^{t}, \mu_{t+1}, y^{t-1}, y_{t}\right)$ claims to cash that pay off in the next period contingent on the aggregate shock $\mu_{t+1}$ and the household's endowment shock $y_{t}$. We let $q\left(\mu^{t}, \mu_{t+1}, y_{t}\right)$ be the price of such a bond that pays one dollar in the asset market in period $t+1$ contingent on the relevant events. Because individual endowments are i.i.d., we assume that these bond prices do not depend on the individual shock history $y^{t-1}$.

Instead of letting each household trade in all possible claims contingent on other households' endowments, we suppose that each household trades only in claims contingent on the household's own endowment with a financial intermediary. This intermediary buys government bonds and trades in the household-specific contingent claims. The latter approach is much less cumbersome than the former and yields the same outcomes. Specifically, the intermediary buys government bonds $B\left(\mu^{t+1}\right)$ and sells household-specific claims of the form $B\left(\mu^{t+1}, y^{t}\right)$ to all the households in order to maximize profits for each aggregate state $\mu^{t+1}$ :

$$
\int_{y^{t}} q\left(\mu^{t+1}, y_{t}\right) B\left(\mu^{t+1}, y^{t-1}, y_{t}\right) f\left(y^{t}\right) d y^{t}-q\left(\mu^{t+1}\right) B\left(\mu^{t}, \mu_{t+1}\right)
$$


subject to the constraint $B\left(\mu^{t+1}\right)=\int_{y^{t}} B\left(\mu^{t+1}, y^{t}\right) f\left(y^{t}\right) d y^{t}$. Arbitrage implies that $q\left(\mu^{t+1}, y_{t}\right)=$ $q\left(\mu^{t+1}\right) f\left(y_{t}\right)$.

Consider now the problem of an individual household. Let $P\left(\mu^{t}\right)$ denote the price level in the goods market in period $t$. In that market, in each period $t \geq 1$, a household starts with real balances $m\left(\mu^{t}, y^{t-1}\right)$. It then chooses transfers of real balances between the goods market and the asset market $x\left(\mu^{t}, y^{t-1}\right)$, an indicator variable $z\left(\mu^{t}, y^{t-1}\right)$ equal to zero if these transfers are zero and one if they are not, and consumption $c\left(\mu^{t}, y^{t-1}\right)$ subject to the cash-in-advance constraint:

$$
c\left(\mu^{t}, y^{t-1}\right)=m\left(\mu^{t}, y^{t-1}\right)+x\left(\mu^{t}, y^{t-1}\right) z\left(\mu^{t}, y^{t-1}\right)
$$

where in (2), when $t=1$, the term $m\left(\mu^{t}, y^{t-1}\right)$ is given by $y_{0} / \mu_{1}$. New money balances in period $t+1$ are given by $m\left(\mu^{t+1}, y^{t}\right)=P\left(\mu^{t}\right) y_{t} / P\left(\mu^{t+1}\right)$.

In the asset market, each period a household starts with contingent claims $B\left(\mu^{t}, y^{t-1}\right)$ to cash delivered in the asset market. The household purchases new bonds and makes cash transfers to or from the goods market subject to the sequence of budget constraints for $t \geq 1$ :

$$
\begin{aligned}
B\left(\mu^{t}, y^{t-1}\right)= & \int_{\mu_{t+1}} \int_{y_{t}} q\left(\mu^{t}, \mu_{t+1}\right) B\left(\mu^{t}, \mu_{t+1}, y^{t-1}, y_{t}\right) f\left(y_{t}\right) d \mu_{t+1} d y_{t} \\
& +P\left(\mu^{t}\right)\left[x\left(\mu^{t}, y^{t-1}\right)+\gamma\right] z\left(\mu^{t}, y^{t-1}\right) .
\end{aligned}
$$

In period $t=0$, this asset market constraint is $\bar{B}=\int_{\mu_{1}} \int_{y_{0}} q\left(\mu_{1}\right) B\left(\mu_{1}, y_{0}\right) f\left(y_{0}\right) d y_{0} d \mu_{1}$. Assume that both consumption and real bond holdings $B\left(\mu^{t}, y^{t-1}\right) / P\left(\mu^{t}\right)$ are uniformly bounded by some large constants.

The problem for a consumer is to maximize utility

$$
\sum_{t=0}^{\infty} \beta^{t} \iint U\left(c\left(\mu^{t}, y^{t-1}\right)\right) g\left(\mu^{t}\right) f\left(y^{t-1}\right) d \mu^{t} d y^{t-1}
$$

subject to the constraints (2)-(3).

The economy has a firm that transfers cash between the asset market and the goods market. Since each transfer of cash consumes $\gamma$ units of goods, the total resource cost of carrying out all transfers at $t$ is $\gamma \int z\left(\mu^{t}, y^{t-1}\right) f\left(y^{t-1}\right) d y^{t-1}$. The firm purchases these goods in the goods market with cash obtained from consumers.

The resource constraint is given by

$$
\int\left[c\left(\mu^{t}, y^{t-1}\right)+\gamma z\left(\mu^{t}, y^{t-1}\right)\right] f\left(y^{t-1}\right) d y^{t-1}=Y
$$


for all $t, \mu^{t}$, and the money market-clearing condition is given by

$$
M\left(\mu^{t}\right) / P\left(\mu^{t}\right)=\int\left(m\left(\mu^{t}, y^{t-1}\right)+\left[x\left(\mu^{t}, y^{t-1}\right)+\gamma\right] z\left(\mu^{t}, y^{t-1}\right)\right) f\left(y^{t-1}\right) d y^{t-1}
$$

for all $t, \mu^{t}$. An equilibrium is defined in the obvious way.

\section{Characterizing Equilibrium}

Here we solve for the equilibrium consumption and real balances of active and inactive households. In the next section, we characterize the link between the consumption of active households and asset prices.

Again, throughout we assume that the cash-in-advance constraint always binds and the households hold only interest-bearing securities in the asset market. Under this assumption, a household's decision to pay the fixed cost to trade in period $t$ affects only its current consumption and bond holdings and not the real balances it holds in the goods market in later periods.

Inactive households simply consume the real balances they currently hold in the goods market. More interesting is the consumption of active households. Since the economy has a complete set of state-contingent bonds, once a household pays the fixed cost to transfer cash between markets, it equates its intertemporal marginal rate of substitution to that of other active households. Since all households are identical ex ante, all active households have a common consumption level $c_{A}\left(\mu^{t}\right)$ that depends only on the aggregate money shock $\mu^{t}$ and not on their idiosyncratic endowments.

We first construct the zones of activity and inactivity for an arbitrary consumption level $c_{A}$, and then we use the resource constraint to determine the equilibrium level. Define the function

$$
h\left(m ; c_{A}\right)=\left[U\left(c_{A}\right)-U(m)\right]-U^{\prime}\left(c_{A}\right)\left(c_{A}+\gamma-m\right)
$$

This function measures the net gain to a household from switching from being an inactive household with consumption $m$ to an active household with consumption $c_{A}$. The first two terms on the right side of (7) measure the direct utility gain within the current period from the switch, while the third term measures the utility cost of the required transfer of real balances from the asset market. With $c_{A}$ fixed, it is optimal for a household with real balances $m$ to trade cash and bonds and consume $c_{A}$ if $h$ is positive and not to trade and instead consume $m$ if $h$ is negative. Note that $h$ is strictly convex in the argument $m$; it attains its minimum at $m=c_{A}$ and is negative at this minimum if $\gamma>0$. Thus, $h$ typically crosses zero twice. 
Define low and high cutoffs for trade $y_{L}\left(c_{A}, \mu\right), y_{H}\left(c_{A}, \mu\right)$ as the solutions to

$$
h\left(\frac{y}{\mu} ; c_{A}\right)=0
$$

when both of these solutions exist. If (7) is negative for all $m<c_{A}$, then set $y_{L}\left(c_{A}, \mu\right)=0$, while if it is negative for all $m>c_{A}$, then set $y_{H}\left(c_{A}, \mu\right)=\infty$. This cutoff rule is illustrated in Figure 2 . Note that as the fixed cost $\gamma$ goes to zero, $y_{L}\left(c_{A}, \mu\right) / \mu$ and $y_{H}\left(c_{A}, \mu\right) / \mu$ converge to $c_{A}$, so that all households become active.

Given this form for the zones of activity and inactivity, we use the resource constraint to determine the equilibrium values of active households' consumption and corresponding cutoffs. Together, the cash-in-advance constraint and constraints (5) and (6) imply that the price level is $P\left(\mu^{t}\right)=M\left(\mu^{t}\right) / Y$, the inflation rate is $\pi_{t}=\mu_{t}$, real money holdings are $m\left(\mu^{t}, y^{t-1}\right)=y_{t-1} / \mu_{t}$, and the consumption of inactive households is $c\left(\mu^{t}, y^{t-1}\right)=y_{t-1} / \mu_{t}$. Substituting the inactive household's consumption into the resource constraint (5) and using the cutoff rule defined in (8) gives

$$
\left(c_{A}+\gamma\right)\left[F\left(y_{L}\right)+1-F\left(y_{H}\right)\right]+\frac{1}{\mu_{t}} \int_{y_{L}}^{y_{H}} y f(y) d y=Y,
$$

where we have suppressed the explicit dependence of $c_{A}, y_{H}$, and $y_{L}$ on $\mu^{t}$. Clearly, these cutoff points and consumption levels of active households depend only on $\mu_{t}$, while the consumption level of inactive households depends only on $\left(\mu_{t}, y_{t-1}\right)$.

If we fix $\mu_{t} \geq 1$ and use (8) to solve for $y_{L}$ and $y_{H}$ as functions of $c_{A}$, we see that the left side of (9) is continuous and strictly monotonic in $c_{A}$. Thus, any solution to the equations for the equilibrium values of active households' consumption and cutoffs is unique. These arguments give the following. (For details, see Appendix A.)

PROPOSITION 1. The equilibrium consumption of households is given by

$$
c\left(\mu^{t}, y^{t-1}\right)= \begin{cases}y_{t-1} / \mu_{t} & \text { if } \quad y_{t-1} \in\left(y_{L}\left(\mu_{t}\right), y_{H}\left(\mu_{t}\right)\right) \\ c_{A}\left(\mu_{t}\right) & \text { otherwise }\end{cases}
$$

where the functions $y_{L}(\mu), y_{H}(\mu), c_{A}(\mu)$ are the solutions to (8) and (9).

In our analysis of asset prices, we can use the sequence of budget constraints (3) to substitute out for the household's bond holdings and replace these constraints with a single period 0 constraint 
on household transfers of cash between the goods and asset markets. As we show in Appendix A, period 0 nominal asset prices are determined by the first-order condition for active households:

$$
\beta^{t} U^{\prime}\left(c_{A}\left(\mu_{t}\right)\right) g\left(\mu^{t}\right)=\lambda Q\left(\mu^{t}\right) P\left(\mu^{t}\right)
$$

where $\lambda$ is the Lagrange multiplier on households' period 0 budget constraint and $Q\left(\mu^{t}\right)$ is the price in dollars in the asset market in period 0 for a dollar delivered in the asset market in period $t$ in state $\mu^{t}$. Since all households are identical in period 0 , the multipliers in the Lagrangian are the same for all of them.

In what follows, we suppress reference to the state $\mu^{t}$ and write the price of an $n$-period bond that costs $q_{t}^{n}$ dollars in period $t$ and pays one dollar in all states in period $t+n$ as

$$
q_{t}^{n}=\int \frac{Q\left(\mu^{t}, \mu^{n}\right)}{Q\left(\mu^{t}\right)} d \mu_{n}=\beta^{n} E_{t} \frac{U^{\prime}\left(c_{A t+n}\right)}{U^{\prime}\left(c_{A t}\right)} \frac{P_{t}}{P_{t+n}}
$$

There is a key difference between this formula and the one that arises in the standard cash-inadvance model. In the standard model, the relevant marginal utility for asset pricing is that of the representative household, and the corresponding consumption is aggregate consumption. Here, the relevant marginal utility for asset pricing in period $t$ is that of the active households in period $t$ and that expected for them in period $t+n$. These marginal utilities in periods $t$ and $t+n$ are not those of any single household, but rather those of whichever households happen to be active in those periods. This distinction is critical for the results that follow.

\section{Asset Prices}

Now we develop the economy's links between money injections and asset prices. The link introduced with market segmentation is how an active household's consumption responds to a money injection. We start with this link and then develop formulas for asset prices.

\section{A. Money Injections and Consumption}

We develop sufficient conditions for a money injection to raise the consumption of active households. We begin with a discrete example and follow with a continuous example.

Consider first a simple example in which $y$ takes on three values, $y_{0}<y_{1}<y_{2}$, with probabilities $f_{0}, f_{1}, f_{2}$, respectively. We conjecture an equilibrium in which, when money growth is $\bar{\mu}$, households with the central value of the endowment $y_{1}$ choose not to trade and those with low and high endowments $y_{0}$ and $y_{2}$ do choose to trade. Under this conjecture, for money growth shocks $\mu$ close to $\bar{\mu}$, we know from the resource constraint that each active household consumes an 
equal share of the active households' aggregate endowment plus the inflation tax levied on inactive households minus the fixed cost, or

$$
c_{A}(\mu)=\frac{y_{0} f_{0}+y_{2} f_{2}}{f_{0}+f_{2}}+\left(1-\frac{1}{\mu}\right) \frac{y_{1} f_{1}}{f_{0}+f_{2}}-\gamma
$$

The corresponding cutoffs $y_{L}\left(c_{A}(\mu), \mu\right), y_{H}\left(c_{A}(\mu), \mu\right)$ are found from (8). This conjecture is valid as long as $y_{0}<y_{L}\left(c_{A}(\bar{\mu}), \bar{\mu}\right)<y_{1}<y_{H}\left(c_{A}(\bar{\mu}), \bar{\mu}\right)<y_{2}$.

Clearly, an increase in the money growth rate $\mu$ raises the inflation tax levied on each inactive household's real balances. In equilibrium, asset prices adjust to redistribute these inflation tax revenues to active households. In this example, the number of active households does not vary with the money injection, so the consumption of each active household increases. Specifically,

$$
\frac{d \log c_{A}}{d \log \mu}=\frac{\left(y_{1} f_{1}\right) / \mu}{c_{A}\left(f_{0}+f_{2}\right)}
$$

which is the ratio of the total consumption of inactive households to that of active households.

Consider next an example in which $y$ has a continuous density. Differentiating (8)-(9) gives

$$
\begin{aligned}
& \left\{\left[F\left(y_{L}\right)+1-F\left(y_{H}\right)\right]+\mu f\left(y_{L}\right)\left(c_{A}+\gamma-\frac{y_{L}}{\mu}\right) \eta_{L}-\mu f\left(y_{H}\right)\left(c_{A}+\gamma-\frac{y_{H}}{\mu}\right) \eta_{H}\right\} \frac{d c_{A}}{d \mu} \\
& =\frac{1}{\mu} \int_{y_{L}}^{y_{H}} \frac{y}{\mu} f(y) d y+\left(\frac{y_{L}}{\mu}-c_{A}-\gamma\right) f\left(y_{L}\right) \frac{y_{L}}{\mu}+\left(c_{A}+\gamma-\frac{y_{H}}{\mu}\right) f\left(y_{H}\right) \frac{y_{H}}{\mu},
\end{aligned}
$$

where $\eta_{i}=U^{\prime \prime}\left(c_{A}\right)\left[c_{A}+\gamma-\left(y_{i} / \mu\right)\right] /\left[U^{\prime}\left(c_{A}\right)-U^{\prime}\left(y_{i} / \mu\right)\right]$. From (8) we know that $y_{L} / \mu<c_{A}<$ $\left(y_{H} / \mu\right)-\gamma$. Thus, $\eta_{H}$ and $\eta_{L}$ are positive and so is the term in braces on the left side of (14). On the right side of (14), the first term is positive and the last two terms are negative, so without further restrictions, the sign of the right side is ambiguous. The first term measures the effect of the inflation tax on the consumption of inactive households when the zone of inactivity is held fixed. The last two terms measure the change in the consumption of inactive households that results from a change in the zone of inactivity. The fraction $f\left(y_{L}\right)$ of households at the lower edge of the zone with real balances $y_{L} / \mu$ become active, and the fraction $f\left(y_{H}\right)$ of households at the upper edge of the zone with real balances $y_{H} / \mu$ become inactive. As long as the fraction of households at these edges is not too large, the consumption of active households increases.

For example, when $y$ is uniform on $[0,1]$ and $y_{i}$ are in $(0,1)$, the right side of (14) simplifies to $\left(y_{H}-y_{L}\right)\left(c_{A}+\gamma\right) / \mu$, which is positive. Thus, under these restrictions, $d c_{A} / d \log \mu$ is positive. In Appendix B, we give an example in which $d c_{A} / d \log \mu$ is positive and $y$ has a $\log$-normal 
distribution. Examples can, of course, also be constructed in which the fraction of households at the edges of the zone is large and an increase in money growth decreases the consumption of active households. Here, though, we focus on what we consider the standard case when the opposite holds.

\section{B. Money Injections and Asset Prices}

We now turn to the link between money injections and asset prices. In order to get analytical results, we make several assumptions. Let the $\log$ of money growth in period $t$ be normally distributed and have constant conditional variance over time. Let $\bar{\mu}$ be defined by $\log \bar{\mu}=E \log \mu_{t}$, where $E$ is the unconditional expectation. Let $U(c)=c^{1-\sigma} /(1-\sigma)$, where the risk aversion parameter $\sigma>0$. Let $\bar{c}_{A}$ denote the consumption of active households when money growth is equal to $\bar{\mu}$. To a first-order approximation, the $\log$ of an active household's marginal utility is given by $\log U^{\prime}\left(c_{A t}\right)=\log U^{\prime}\left(\bar{c}_{A}\right)-\phi\left(\log \mu_{t}-\log \bar{\mu}\right)$, where

$$
\phi=\sigma \frac{d \log c_{A}}{d \log \mu}
$$

evaluated at $\mu=\bar{\mu}$. The parameter $\phi$ is the elasticity of an active household's marginal utility with respect to a money injection. Given these assumptions, we will analyze the relation between money and interest rates.

\section{Interest Rate Dynamics}

Now we illustrate the dynamics of money injections, expected inflation, and interest rates. We first show that the model can produce the negative relation between expected inflation and real interest rates noted by Barr and Campbell (1997). We then give conditions under which the effect of money injections on real interest rates dominates their effect on expected inflation, so that money injections have liquidity effects.

We work out the model's implications for the dynamics of the interest rate term structure for two common processes for money growth and inflation: an autoregressive process and a longmemory process. We begin with the autoregressive process because it is simple and it generates the well-known Vasicek (1977) model for the dynamics of the term structure. Moreover, according to Christiano, Eichenbaum, and Evans (1998), autoregressive processes do a good job of approximating the responses of money growth and interest rates to a money shock. Using a different VAR, however, Cochrane (1994) has found a more protracted response for money growth to a 
money shock. We model this as a long-memory process. We show that with such a process, a money injection leads to a fall in the short-term nominal rate followed by a rise. We show that the shock also twists the yield curve: on impact, short rates fall and long rates rise. At least since Friedman (1968), economists have argued that money injections have these effects on interest rates. Moreover, Cochrane (1994) has found such a response for interest rates in his VAR.

Throughout the following analysis, money injections have two effects on nominal interest rates: an expected inflation effect and a segmentation effect, as can be seen from the Fisher equation: $\hat{\imath}_{t}=\hat{r}_{t}+E_{t} \hat{\pi}_{t+1}$, where $i$ is the nominal interest rate and $r$ is the real interest rate. (Here and elsewhere, a caret over a character denotes a log-deviation.) Using a log-linear approximation to (11), we can express the expected inflation effect as

$$
E_{t} \hat{\pi}_{t+1}=E_{t} \hat{\mu}_{t+1}
$$

and the segmentation effect as

$$
\hat{r}_{t}=\phi\left(E_{t} \hat{\mu}_{t+1}-\hat{\mu}_{t}\right)
$$

where $\phi \hat{\mu}_{t}$ and $\phi E_{t} \hat{\mu}_{t+1}$ are the effects of the money injection on the active households' marginal utility in periods $t$ and $t+1$.

In the standard model, $\gamma=0$, so $\phi=0$ and real interest rates are constant. In our model, $\gamma>0$, so $\phi>0$; thus, a money growth shock that increases $\mu_{t}$ also increases the consumption of active households in $t$ and drives down their marginal utility in $t$. If the money growth shock raises expected money growth in $t+1$ as well, then it raises consumption and lowers marginal utility for active households in $t+1$. As long as the money growth process is mean-reverting, so that $E_{t} \hat{\mu}_{t+1}-\hat{\mu}_{t}$ is decreasing in $\hat{\mu}_{t}$, an increase in money growth drives down real interest rates. With such processes, the model reproduces the negative relation between expected inflation and real rates found by Barr and Campbell (1997), since a money injection drives expected inflation up and real rates down.

Our model produces liquidity effects when the segmentation effect (17) dominates the expected inflation effect (16). The overall magnitude of the segmentation effect depends on two parameters: the elasticity of the marginal utility of active households with respect to money growth $\phi$ and the persistence of a money growth shock as measured by $E_{t} \hat{\mu}_{t+1}-\hat{\mu}_{t}$. The segmentation effect increases the higher is $\phi$, that is, the more responsive is an active household's marginal 
utility to a money injection. This effect is smaller the greater is the persistence of money growth. If money growth is temporary, then a given money injection will lead to a temporary increase in active households' consumption and, hence, to a relatively large drop in the real interest rate. As the shock to money growth becomes more persistent, a given money injection leads to a more permanent increase in active households' consumption and, hence, to a smaller drop in the real interest rate.

We turn now to an analysis of the two common processes for money growth and inflation.

\section{Example 1. Autoregressive Process}

Assume that money injections satisfy $\hat{\mu}_{t+1}=\rho \hat{\mu}_{t}+\varepsilon_{t+1}$, where $\rho$ is the persistence of the money shock and $\varepsilon_{t+1}$ is a normal, i.i.d. innovation with mean zero and variance $\sigma_{\epsilon}^{2}$. The expected inflation effect is given by $E_{t} \hat{\pi}_{t+1}=\rho \hat{\mu}_{t}$, while the segmentation effect is given by $\hat{r}_{t}=\phi(\rho-1) \hat{\mu}_{t}$. As long as money growth is mean-reverting, so that $\rho<1$, expected inflation and real rates move in the opposite direction. Notice that if

$$
\phi>\frac{\rho}{1-\rho},
$$

then the segmentation effect dominates the expected inflation effect, and a money injection leads to a fall in nominal interest rates on impact.

Consider next the dynamics of the short-term interest rate. Since $E_{t} \hat{\pi}_{t+k+1}=\rho^{k} E_{t} \hat{\pi}_{t+1}$ and $E_{t} \hat{r}_{t+k}=\rho^{k} \hat{r}_{t}$, we have that $E_{t} \hat{\imath}_{t+k}=\rho^{k} \hat{\imath}_{t}$. Thus, real and nominal interest rates have the same persistence as do money shocks. If (18) holds, then a money injection leads nominal rates to initially fall and decay back to zero at rate $\rho$. Clearly, these liquidity effects are persistent whenever money shocks are persistent.

Consider the effects on the yield curve. In our model, the dynamics of the term structure satisfies the expectations hypothesis: movements in long-term rates are an average of movements in expected future short-term rates. In fact, this is true for any log-linear model with constant conditional variances. ${ }^{2}$ When (18) holds, so that the segmentation effect dominates the expected inflation effect, a money injection lowers the shorter yields by more than the longer yields and thus steepens the yield curve. Each yield follows an autoregressive process and returns to its mean value at rate $\rho$. For this example, then, our general equilibrium model generates the dynamics of the term structure summarized by the Vasicek (1977) model.

Consider the magnitude of $\phi$ required for liquidity effects for this autoregressive example. 
Christiano, Eichenbaum, and Evans (1998) argue that the impulse response for M2 growth following a money shock is well-approximated by an autoregressive process with $\rho=.5$. With this persistence, (18) implies that the model produces liquidity effects for $\phi \geq 1$. Getting a handle on the level of segmentation in the data is harder. To get a rough feel for what different levels of $\phi$ entail, note that combining the formula from our discrete example (13) with equation (15) gives that

$$
\phi=\sigma \frac{\text { Total consumption of inactive households }}{\text { Total consumption of active households }} \text {. }
$$

Consider $\phi=2$. In order to interpret this value, we need to take a stand on the risk aversion parameter $\sigma$. The literature uses a wide range of estimates for $\sigma$. The business cycle literature commonly uses $\sigma=2$, but estimates easily range as high as $\sigma=8$. With $\sigma=2$, (19) implies that we need half of the households to be not actively trading money for interest-bearing assets in any given period in order to generate $\phi=2$. With $\sigma=8$, we only need one-fifth of the households to be inactive in order to get $\phi=2$.

We illustrate the model's predictions in Figure 3. In the top panel of the figure, we graph the impulse responses to a money shock of money growth and (annualized) short-term nominal interest rates with $\phi=2$. The responses are similar to those found by Christiano, Eichenbaum, and Evans (1998) using M2. In the bottom panel of Figure 3, we graph the yield curves at three different times: at the time of the shock's impact, one quarter after the shock, and three quarters after the shock. These responses show the yield curve steepening on impact and then reverting slowly to its normal position. Since interest rates in the model satisfy the expectations hypothesis, the impulse response plot for the short-term rate completely determines the dynamics of yields of long maturities. (Actually, the impulse response of $E_{t} i_{t+k}$ is the response of the one-period forward rate of maturity $k$ in period $t$, and the yields are just averages of the forward rates.) So the plots in the two panels of Figure 3 are just two ways to summarize the same information.

\section{EXAMPLE 2. Long-Memory Process}

In Cochrane (1994), the impulse response for M2 decays more slowly than does an autoregressive process. We model this slow decay with a long-memory process.

Consider the moving-average process $\hat{\mu}_{t}=\sum_{j=0}^{\infty} \theta_{j} \varepsilon_{t-j}$, where $\theta_{j}$ are the moving-average coefficients and $\varepsilon_{t}$ is a white noise process. The long-memory process is a moving-average process in which the coefficients satisfy the recursion $\theta_{j}=\left(1-\frac{1-d}{j}\right) \theta_{j-1}$ for $j \geq 1$ and $-1 / 2<d<1 / 2$, 
and the $\varepsilon_{t-j}$ are independent and distributed $N\left(0, \sigma_{\varepsilon}^{2}\right)$. The parameter $d$ controls the rate of decay of the moving-average coefficients. These coefficients decay at a rate $(1-d) / j<1$. For large $j$, this rate approaches zero, which is the source of the long memory.

Using (16)-(17), we can easily show that the short-term nominal interest rate $\hat{\imath}_{t}=\sum_{j=1}^{\infty} \alpha_{j} \varepsilon_{t+1-j}$, where

$$
\alpha_{j}=\left[-\phi \frac{(1-d)}{j}+\left(1-\frac{(1-d)}{j}\right)\right] \theta_{j-1} .
$$

Here, in the brackets, the first term is the segmentation effect and the second is the expected inflation effect. Since the coefficients $\theta_{j}$ are all positive, for large enough $j$ the expected inflation effect must dominate the segmentation effect, and $\alpha_{j}$ must be positive. If $\phi>d /(1-d)$, then for $j=1$, the segmentation effect outweighs the expected inflation effect, and so for small $j, \alpha_{j}$ is negative. If we ignore integers, we see that $\alpha_{j}$ goes from negative to positive at $j^{*}=(1+\phi)(1-d)$. Notice that the more segmented is the market, the longer is the period in which the segmentation effect outweighs the expected inflation effect.

We illustrate the pattern implied by the long-memory process with $d=1 / 4$ and $\phi=2$ in Figure 4. In the top panel, we see that the nominal rate drops on the money shock's impact and then rises in the third quarter after the shock. Interestingly, this pattern is similar to that estimated by Cochrane (1998), which he argues is representative of results in the VAR literature. In the bottom panel, we plot the yield curves on impact, one quarter after the shock, and three quarters after the shock. In this figure, we see that on impact, the money growth shock twists the yield curve, lowering short yields and raising long ones. After several quarters, short yields rise and all yields slowly move back to their average values.

\section{Exchange Rates}

Having demonstrated that our segmented market model can reproduce the major observed interest rate responses to money injections, we turn now to exchange rates. Here the features we want to reproduce are different for countries with different rates of inflation. In low inflation countries, real and nominal exchange rates have similar volatility, are highly correlated, and are persistent. (See Mussa 1986 and our Table 1.) In high inflation countries, nominal exchange rates are substantially more volatile than real exchange rates. (See Figure 6.) The standard model cannot reproduce these observations. We develop a two-country version of our segmented markets economy that can. 


\section{A. A Two-Country Economy}

First we develop a more sophisticated representation of monetary policy than we used in the onecountry model. Earlier we explored the implications of the one-country model only for the impulse responses to exogenous money shocks. Here we explore the model's predictions for some unconditional moments of the data, so we need to take a firmer stand on the policy rule followed by the monetary authority. As we document below, in the data, nominal interest rates are substantially more persistent than money growth rates. To capture this, we model money growth as the sum of an exogenous component and an endogenous component which offsets a type of money demand shock.

Consider now a two-country, cash-in-advance economy that extends the work of Lucas (1982). We refer to one country as the home country and the other as the foreign country. For simplicity, we abstract from trade in goods by having the households in each country desire only the local good. Specifically, households in the home country use the home currency, called dollars, to purchase a home good. Households in the foreign country use the foreign currency, called euros, to purchase a foreign good. In the asset market, households trade the two currencies and dollar and euro bonds which promise delivery of the relevant currency in the asset market in the next period, and the two governments introduce their currencies via open market operations. As before, each transfer of cash between the asset market and any individual household in either goods market has a real fixed cost of $\gamma$.

In order to generate a type of money demand shock, we allow shocks to the distribution of idiosyncratic endowments in the two countries. The densities of the endowments are now given by $f\left(y ; \theta_{t}\right)$ and $f\left(y^{*} ; \theta_{t}^{*}\right)$, where $\theta_{t}$ and $\theta_{t}^{*}$ are i.i.d. shocks, both with mean $\bar{\theta}$. Thus, the aggregate shock is $s_{t}=\left(\mu_{t}, \mu_{t}^{*}, \theta_{t}, \theta_{t}^{*}\right)$, and $s^{t}=\left(s_{1}, \ldots, s_{t}\right)$ is its history. Let $g\left(s^{t}\right)$ denote the density of the probability distribution over such histories.

We let home households trade a complete set of dollar-denominated claims with a world intermediary, and we let foreign households similarly trade euro-denominated claims. The home government's bonds are dollar bonds, and its budget constraint is (1) as before. The foreign government's bonds are euro bonds, and its budget constraint is the obvious analog. The world intermediary buys both dollar- and euro-denominated government bonds and trades in both dollar and euro household-specific contingent claims in order to maximize profits for each aggregate state $s^{t+1}$. Lack of arbitrage across currencies implies that $q\left(s^{t}, s_{t+1}\right)=q^{*}\left(s^{t}, s_{t+1}\right) e\left(s^{t}\right) / e\left(s^{t+1}\right)$. Here $q$ 
and $q^{*}$ are the prices for one-period dollar and euro bonds and $e$ is the nominal exchange rate in terms of dollars per euro. We use this relationship to solve for movements in nominal exchange rates.

To solve for the period 0 nominal exchange rate $e_{0}$, we need to choose the initial conditions carefully. In period 0 , home households have $\bar{B}_{h}$ units of the home government debt and $\bar{B}_{h}^{*}$ units of the foreign government debt, which are claims on $\bar{B}_{h}$ dollars and $\bar{B}_{h}^{*}$ euros in the asset market in that period. In period 0 , there is no trade in goods; households simply trade bonds. Likewise, foreign households start period 0 with $\bar{B}_{f}$ units of the home government debt and $\bar{B}_{f}^{*}$ units of the foreign government debt in the asset market. We require that $\bar{B}_{h}+\bar{B}_{f}=\bar{B}$ and $\bar{B}_{h}^{*}+\bar{B}_{f}^{*}=\bar{B}^{*}$, where $\bar{B}$ is the initial stock of home government debt in dollars and $\bar{B}^{*}$ is the initial stock of foreign government debt in euros.

The constraints for the home households are the same as before except that now, in period $0,(3)$ is given by $\bar{B}_{h}+e_{0} \bar{B}_{h}^{*}=\int_{s_{1}} \int_{y_{0}} q\left(s_{1}\right) B\left(s_{1}, y_{0}\right) f\left(y_{0}\right) d s_{1} d y_{0}$. The constraints for the foreign households are the obvious analogs, with the foreign households having initial assets of $\left(\bar{B}_{f} / e_{0}\right)+\bar{B}_{f}^{*}$ in euros in period 0 . The resource constraint for the home good and the money market-clearing conditions for dollars are similar to those in (5) and (6) except that the distribution of endowments is now indexed by the current realization $\theta_{t}$. Analogous constraints hold for the foreign good and euros.

In equilibrium, the period 0 nominal exchange rate $e_{0}=\left(\vec{B}-\bar{B}_{h}\right) / \bar{B}_{h}^{*}$. To see this, iterate on (1) and (3) for the home household, and take limits to show that $\bar{B}=\bar{B}_{h}+e\left(s^{0}\right) \bar{B}_{h}^{*}$. Clearly, this exchange rate $e_{0}$ exists and is positive as long as $\bar{B}_{h}<\bar{B}$ and $\bar{B}_{h}^{*}>0$ or $\bar{B}_{h}>\bar{B}$ and $\bar{B}_{h}^{*}<0$.

The equilibrium consumption of households in the home country is similar to that described in Proposition 1. Specifically, the cutoff rule for trade is the same, but (9) is replaced by

$$
\left(c_{A}+\gamma\right)\left[F\left(y_{L} ; \theta_{t}\right)+1-F\left(y_{H} ; \theta_{t}\right)\right]+\frac{1}{\mu_{t}} \int_{y_{L}}^{y_{H}} y f\left(y ; \theta_{t}\right) d y=Y,
$$

so that the equilibrium consumption of active home households is given by $c_{A}\left(\mu_{t} ; \theta_{t}\right)$. The analogous result holds for households in the foreign country. This implies that active household consumption in the two countries responds only to injections of the local currency and the local shock to endowments.

To develop the asset pricing formulas for this two-country economy, recall from (10) that period 0 nominal dollar asset prices $Q\left(s^{t}\right)$ are given by the marginal utility of a dollar for active home households. Likewise, period 0 euro asset prices $Q^{*}\left(s^{t}\right)$ are given by the analogous marginal 
utility for active foreign households. Arbitrage requires that nominal exchange rates satisfy $e\left(s^{t}\right)=$ $e_{0} Q^{*}\left(s^{t}\right) / Q\left(s^{t}\right)$. We define the real exchange rate as $x\left(s^{t}\right)=e\left(s^{t}\right) P^{*}\left(s^{t}\right) / P\left(s^{t}\right)$, which is then given by

$$
x\left(s^{t}\right)=e_{0} \frac{\lambda}{\lambda^{*}} \frac{U^{\prime}\left(c_{A}^{*}\left(\mu_{t}^{*} ; \theta_{t}^{*}\right)\right)}{U^{\prime}\left(c_{A}\left(\mu_{t} ; \theta_{t}\right)\right)} .
$$

Since $P\left(s^{t}\right)=M\left(s^{t}\right) / Y$, and likewise for $P^{*}$, the nominal exchange rate is $e\left(s^{t}\right)=x\left(s^{t}\right) M\left(s^{t}\right) / M^{*}\left(s^{t}\right)$. In period $t$ in aggregate state $s^{t}$, state-contingent dollar bond prices are given by (11) and likewise for state-contingent euro bond prices.

\section{B. Exchange Rates With Low Inflation}

Now we describe a process for monetary policy relevant for low inflation countries and derive the model's implications for the volatility and persistence of exchange rates.

In the data, interest rates are much more persistent than money growth. Yet recall from Example 1 that in the simple model with only money shocks, interest rates and money growth are equally persistent. A simple way to address this discrepancy between the data and the simple model is to assume that part of monetary policy is exogenous and persistent while another part is endogenous and offsets transient money demand shocks. The endogenous part essentially adds a transient component to money growth that does not appear in interest rates.

In our two-country model, therefore, we assume that the monetary authority follows an interest rate policy of the form $\hat{\imath}_{t+1}=\rho \hat{\imath}_{t}+\varepsilon_{t+1}$. It implements this policy rule by choosing money growth to be the sum of two components:

$$
\hat{\mu}_{t}=\hat{\mu}_{1 t}+v\left(\mu_{1 t}, \theta_{t}\right),
$$

where $\mu_{1 t}$ is the exogenous part of monetary policy that follows an autoregressive process $\hat{\mu}_{1 t+1}=$ $\rho \hat{\mu}_{1 t}+\varepsilon_{\mu t+1}$ and $v\left(\mu_{1 t}, \theta_{t}\right)$ is the endogenous part of monetary policy that offsets the shock $\theta_{t}$ to endowments. Thus, $v\left(\mu_{1 t}, \theta_{t}\right)$ solves $c_{A}\left(\mu_{1 t}+\left(\mu_{1 t}, \theta_{t}\right) ; \theta_{t}\right)=c_{A}\left(\mu_{1 t} ; \bar{\theta}\right)$, so that, in equilibrium, the consumption of active households does not respond to the shock $\theta_{t}$. Clearly, $\partial v\left(\mu_{1}, \bar{\theta}\right) / \partial \mu_{1}=0$. In what follows, we suppress all references to $\bar{\theta}$ and instead write the consumption of active households as $c_{A}\left(\mu_{1 t}\right)$. We assume that foreign money growth is set in a similar way and that the shocks to both the exogenous and endogenous parts of foreign monetary policy are independent of those to home monetary policy.

To a first-order approximation, the $\log$ of $v$ is given by $\hat{v}_{t}=\eta \hat{\theta}_{t}$. The $\log$ of the marginal utility of consumption for active home households is given as before, with $\phi$ defined as in (15), 
with $\mu_{1}$ replacing $\mu$. The log of the marginal utility of consumption for active foreign households is approximated in the analogous fashion, with $\phi^{*}$ being the elasticity of the marginal utility of active foreign households with respect to a foreign money injection.

We have from (17) that the real interest rate depends only on the exogenous part of monetary policy. Thus, $\hat{r}_{t}=\phi(\rho-1) \hat{\mu}_{1 t}$. In contrast, inflation and money growth depend on both components and are given by $\hat{\pi}_{t+1}=\hat{\mu}_{t+1}=\hat{\mu}_{1 t}+\eta \hat{\theta}_{t}$. To see that the money growth rate rule in (22) implements the assumed interest rate rule, note that since $E_{t} \pi_{t+1}=\rho \hat{\mu}_{1 t}$, the nominal interest rate is

$$
\hat{\imath}_{t}=\hat{r}_{t}+E_{t} \hat{\pi}_{t+1}=[\phi(\rho-1)+\rho] \hat{\mu}_{1 t} .
$$

Thus, the serial correlation of the nominal interest rate is $\rho$ while the serial correlation of inflation is lower than $\rho$ because of the i.i.d. component from money demand shocks.

Consider the implications of this model for the behavior of real exchange rates. Equation (21) implies that

$$
\hat{x}_{t}=\phi \hat{\mu}_{1 t}-\phi^{*} \hat{\mu}_{1 t}^{*}
$$

Clearly, then, the more segmented a market is, the greater is the volatility of real exchange rates. Moreover, the persistence of real exchange rates is determined by the persistence of the interest rate rule.

To get a feel for the quantitative implications of the model, consider a simple numerical example. We set $\rho=.95$, which is the serial correlation of the U.S. federal funds rate on a quarterly basis $(1960: 1-1999: 3) .{ }^{3}$ We choose $\eta \operatorname{std}(\hat{\theta})$ so that the serial correlation of money growth is .75, which is the serial correlation of quarterly M2 growth (1960:1-1999:3). We assume symmetry across countries, so that $\phi=\phi^{*}$, and we assume that shocks are independent across countries. We simulate the model for 120 time periods, HP-filter the data, and consider the mean values of several statistics over 50 simulations.

In Figure 5, we plot against $\phi$ three statistics based on these simulations: the standard deviation of the nominal exchange rate relative to that of the real exchange rate $[\operatorname{std}(\log e) / \operatorname{std}(\log x)]$, the correlation of the real and nominal exchange rates $[\operatorname{corr}(\log e, \log x)]$, and the serial correlation (or persistence) of the real exchange rate $\left[\operatorname{corr}\left(\log x, \log x_{-1}\right)\right]$. We see that as $\phi$ becomes large, the volatility of the real exchange rate becomes closer to that of the nominal exchange rate, and the correlation of the real and nominal rates grows. We also see that real exchange rates essentially inherit the persistence of nominal interest rates regardless of $\phi$. 
In Table 1 we report on these same three statistics for a number of low inflation countries. Comparing Figure 5 to Table 1, we see that as the segmentation parameter is increased to 6 , the relative volatility and the correlation of nominal and real exchange rates in the model begin to approach 1, the level that both approximate in the data. The persistence of real exchange rates in the model is similar to that in the data (around .8) for any value of the segmentation parameter.

The numbers in this example are useful to give a feel for how the model works with a moderate amount of segmentation. Clearly, to do a more complete comparison between the model and the data, we would need to include real shocks, which would raise the volatility of real exchange rates.

\section{Exchange Rates With High Inflation}

Now we shift to high inflation countries. We first document that in high inflation countries, the volatility of nominal exchange rates is substantially greater than that of real exchange rates, while in low inflation countries, these volatilities are similar. This difference is obvious in Figure 6, which displays the ratio of the standard deviations of the nominal and real exchange rates based on HPfiltered data for 41 countries. ${ }^{4}$ In this section, we discuss how the degree of market segmentation, as measured by the parameter $\phi$, varies with the average rate of money growth. In particular, we show that if the average rate of inflation is high enough, almost all households choose to pay the fixed cost, so that asset markets are no longer segmented. Thus, as inflation becomes high enough, the volatility of real exchange rates becomes much smaller than that of nominal exchange rates.

For simplicity, consider again an example in which $y$ takes on three values, $y_{0}<y_{1}<y_{2}$, with probabilities $f_{0}, f_{1}, f_{2}$, respectively, and we hold the money demand shock $\theta$ constant. Consider the degree of segmentation in a country with low average inflation $\bar{\mu}_{A}$ and in a country with high average inflation $\bar{\mu}_{B}$. For the low inflation country, assume that $y_{0}<y_{L}\left(c_{A}\left(\bar{\mu}_{A}\right), \bar{\mu}_{A}\right)<y_{1}<$ $y_{H}\left(c_{A}\left(\bar{\mu}_{A}\right), \bar{\mu}_{A}\right)<y_{2}$. With a utility function of the form $U(c)=c^{1-\sigma} /(1-\sigma)$,

$$
\phi=\sigma \frac{d \log c_{A}}{d \log \mu}=\frac{\sigma\left(y_{1} f_{1}\right) / \bar{\mu}_{A}}{c_{A}\left(f_{0}+f_{2}\right)} .
$$

For the high inflation country, we proceed as follows. Under an assumption that households' utility is sufficiently curved, we can show that there exists a high enough inflation rate such that all households pay the fixed cost. More formally, we have

PROPOSITION 2. Assume that the support of $y$ is bounded by $\bar{y}$ and that $1-\sigma<\frac{Y-\gamma}{Y}$. Then a sufficiently high inflation rate exists such that all households are traders and $\phi=0$. 
Proof. Let $x_{L} \in[0, Y-\gamma]$ be the solution to $h(x ; Y-\gamma)=0$. We first show that, under our assumption on $\sigma$, this solution with $x_{L}>0$ exists. Then we show that when $\bar{\mu}_{B}>\bar{y} / x_{L}$, all households choose to pay the fixed cost to trade.

To show that $x_{L}>0$, we need to show that there is a solution to $h(x ; Y-\gamma)=0$ in the interval $(0, Y-\gamma)$. Recall that $h(x ; Y-\gamma)$ is minimized at $x=Y-\gamma$ and is negative at this point. Thus, we need only show that $h(0 ; Y-\gamma)>0$. The condition on $\sigma$ ensures that this inequality holds. Note that $h(0 ; Y-\gamma) \leq 0$ if that condition is violated.

To see that all households choose to trade when $\bar{\mu}_{B}>\bar{y} / x_{L}$, observe that $c_{A}=Y-\gamma$, that $y_{L}=x_{L} \bar{\mu}_{B}, y_{H}=x_{H} \bar{\mu}_{B}$ solve (7) and (9), and that $y_{L}>\bar{y}$. Thus, we know that traders' consumption does not depend on money growth $\mu$ and $\phi=0$.

Proposition 2 implies that as inflation becomes sufficiently high, the segmentation effect diminishes and real exchange rates become much less volatile than nominal exchange rates. One can construct examples in which the segmentation parameter $\phi$ declines smoothly with $\mu$. In this sense, our model can generate the pattern in the data documented in Figure 6.

\section{Conclusion}

We have developed a model in the spirit of Baumol (1952) and Tobin (1956) that captures the idea that when a government injects money through an open market operation, only a fraction of the households in the economy are on the other side of the transaction; hence, money injections have segmentation effects in addition to their standard Fisherian effects. We have deliberately kept the model simple to allow an analytical solution. We have shown that this model generates features of the data which standard models do not: a negative relation between expected inflation and real interest rates and, with moderate amounts of segmentation, both persistent liquidity effects and volatile and persistent exchange rates.

In order to generate volatile real exchange rates, a model needs frictions in both the goods and asset markets. (See, for example, Chari, Kehoe, and McGrattan 1998.) Here we abstract from friction in the goods market, such as sticky prices (for example, Obstfeld and Rogoff 1995), in order to focus on friction in the asset market. Our work thus complements work on goods market frictions and highlights a potentially important component of a complete model of exchange rates with frictions in both types of markets. 


\section{Notes}

${ }^{1}$ An extensive literature dating back at least to Merton (1987) considers asset market segmentation in models without money. See, for example, Hirshleifer (1988), Aiyagari and Gertler (1991), Cuny (1993), Allen and Gale (1994), Balasko, Cass, and Shell (1995), Saito (1996), and Basak and Cuoco (1998) and the references cited therein.

${ }^{2}$ Of course, there is substantial evidence that the expectations hypothesis is a poor approximation of the dynamics of the term structure. (See Campbell, Lo, and MacKinlay 1997.) Addressing that problem, however, is beyond our scope here.

${ }^{3}$ Notice that the unconditional persistence of the federal funds rate is much higher than the conditional response of that rate following a money shock as estimated by Christiano, Eichenbaum, and Evans (1998). They argue that the monetary authority sets interest rates as a function of some other variables in the economy which are very persistent. Here we abstract from those other variables, so we simply make the interest rates follow a highly persistent $\operatorname{AR}(1)$ process.

${ }^{4}$ We use the International Monetary Fund's data from its publication International Financial Statistics covering the period 1970:1-1999:3 for the following countries: Argentina, Australia, Austria, Belgium, Brazil, Canada, Chile, Colombia, Denmark, Finland, France, Germany, Greece, Hong Kong, Hungary, India, Indonesia, Ireland, Israel, Italy, Japan, Korea, Malaysia, Mexico, the Netherlands, New Zealand, Norway, Peru, the Philippines, Poland, Portugal, Singapore, South Africa, Spain, Sweden, Switzerland, Taiwan, Thailand, Turkey, the United Kingdom, and Venezuela. For each country, we use the bilateral nominal exchange rate and the consumer price index-based bilateral real exchange rate with the United States. 


\section{Appendix A}

In this appendix, we provide sufficient conditions to ensure that households never carry over cash in either the goods market or the asset market.

To allow for the possibility that a household may hold cash, we modify the household constraints as follows. In the goods markets, we denote unspent real balances that the shopper might carry over from goods shopping by $a\left(\mu^{t}, y^{t-1}\right)$. We rewrite the constraint (2) as

$$
a\left(\mu^{t}, y^{t-1}\right)=m\left(\mu^{t}, y^{t-1}\right)+x\left(\mu^{t}, y^{t-1}\right) z\left(\mu^{t}, y^{t-1}\right)-c\left(\mu^{t}, y^{t-1}\right)
$$

We write new money balances as $m\left(\mu^{t+1}, y^{t}\right)=P\left(\mu^{t}\right)\left[y_{t}+a\left(\mu^{t}, y^{t-1}\right)\right] / P\left(\mu^{t+1}\right)$ and add the cash-in-advance constraint $a\left(\mu^{t}, y^{t-1}\right) \geq 0$. In the asset market, we replace the budget constraints (3) with the sequence of budget constraints for $t \geq 1$ :

$$
\begin{aligned}
B\left(\mu^{t}, y^{t-1}\right)= & \int_{\mu_{t+1}} \int_{y_{t}} q\left(\mu^{t}, \mu_{t+1}\right) B\left(\mu^{t}, \mu_{t+1}, y^{t-1}, y_{t}\right) f\left(y_{t}\right) d \mu_{t+1} d y_{t}+ \\
& N\left(\mu^{t}, y^{t-1}\right)-N\left(\mu^{t-1}, y^{t-2}\right)+P\left(\mu^{t}\right)\left[x\left(\mu^{t}, y^{t-1}\right)+\gamma\right] z\left(\mu^{t}, y^{t-1}\right)
\end{aligned}
$$

where $N\left(\mu^{t-1}, y^{t-2}\right)$ is cash held over from the previous asset market and $N\left(\mu^{t}, y^{t-1}\right)$ is cash held over into the next asset market. Let $N\left(\mu^{t}, y^{t-1}\right) \geq 0$ and $N\left(\mu^{t-1}, y^{t-2}\right)=N_{0}$ in period $t=1$. In period $t=0$, this asset market constraint is $\bar{B}=\int_{\mu_{1}} \int_{y_{0}} q\left(\mu_{1}\right) B\left(\mu_{1}, y_{0}\right) f\left(y_{0}\right) d y_{0} d \mu_{1}+N_{0}$. Otherwise, the household's problem is unchanged.

We develop our sufficient conditions in several steps. We first characterize the household's optimal choice of $c$ and $x$ given prices and arbitrary rules for $m, a$, and $z$ and summarize these results in Lemma 1. We then characterize the household's trading rule $z$ given an arbitrary rule for $m, a$ and the optimal rules for $c$ and $x$, and we summarize these results in Lemma 2. These lemmas complete the proof of Proposition 1 in the text. In Lemma 3, we provide sufficient conditions on the money growth process and the endowments process to ensure that $a$ and $N$ are always zero.

Start by using the sequence of budget constraints (26) to substitute out for the household's bond holdings. Replace these constraints with a single period 0 constraint on household transfers of cash between the goods and asset markets. Any bounded allocation and bond holdings that satisfy (26) also satisfy a period 0 budget constraint:

$$
\sum_{t=0}^{\infty} \int Q\left(\mu^{t}\right) \int_{y^{t-1}}\left\{P\left(\mu^{t}\right)\left[x\left(\mu^{t}, y^{t-1}\right)+\gamma\right] z\left(\mu^{t}, y^{t-1}\right)+\right.
$$




$$
\left.N\left(\mu^{t}, y^{t-1}\right)-N\left(\mu^{t}, y^{t-2}\right)\right\} f\left(y^{t-1}\right) d y^{t-1} d \mu^{t} \leq \bar{B}
$$

Thus, the household's problem can be restated as follows. Choose real money holdings $m$ and $a$, trading rule $z$, consumption and transfers $c$ and $x$, and cash in the asset market $N$, subject to constraints (25) and (27) and the cash-in-advance constraint.

Consider now a household's optimal choice of consumption $c\left(\mu^{t}, y^{t-1}\right)$ and transfers of dollar real balances $x\left(\mu^{t}, y^{t-1}\right)$ given prices $Q\left(\mu^{t}\right), P\left(\mu^{t}\right)$, arbitrary feasible choices of real money holdings $m\left(\mu^{t}, y^{t-1}\right)$ and $a\left(\mu^{t}, y^{t-1}\right)$, and a trading rule $z\left(\mu^{t}, y^{t-1}\right)$. These choices maximize the Lagrangian corresponding to the household's problem. Let $\nu\left(\mu^{t}, y^{t-1}\right)$ be the multiplier on (25) and $\lambda$ be the multiplier on (27). The first-order condition corresponding to $c$ and $x$ respectively are then given by $\beta^{t} U^{\prime}\left(c\left(\mu^{t}, y^{t-1}\right)\right) g\left(\mu^{t}\right) f\left(y^{t-1}\right)=\nu\left(\mu^{t}, y^{t-1}\right)$ and $\lambda Q\left(\mu^{t}\right) P\left(\mu^{t}\right) z\left(\mu^{t}, y^{t-1}\right) f\left(y^{t-1}\right)=$ $\nu\left(\mu^{t}, y^{t-1}\right) z\left(\mu^{t}, y^{t-1}\right)$. For those states such that $z\left(\mu^{t}, y^{t-1}\right)=1$, these two first-order conditions imply that $\beta^{t} U^{\prime}\left(c\left(\mu^{t}, y^{t-1}\right)\right) g\left(\mu^{t}\right)=\lambda Q\left(\mu^{t}\right) P\left(\mu^{t}\right)$. Since all households are identical in period 0 , the multipliers in the Lagrangian are the same for all households. We summarize this discussion as follows:

LEMMA 1. All households that choose to pay the fixed cost for a given aggregate state $\mu^{t}$ have identical consumption $c\left(\mu^{t}, y^{t-1}\right)=c_{A}\left(\mu^{t}\right)$ for some function $c_{A}$. Households that choose not to pay the fixed cost have consumption $c\left(\mu^{t}, y^{t-1}\right)=m\left(\mu^{t}, y^{t-1}\right)-a\left(\mu^{t}, y^{t-1}\right)$.

Next consider a household's optimal choice of whether to pay the fixed cost to trade given prices $Q\left(\mu^{t}\right), P\left(\mu^{t}\right)$ and its arbitrary feasible choices of real money holdings in the goods market $m\left(\mu^{t}, y^{t-1}\right), a\left(\mu^{t}, y^{t-1}\right)$. From Lemma 1, we have the form of the optimal consumption and transfer rules corresponding to the choices of $z=1$ and $z=0$. Substituting these rules into (4) and (27) gives the problem of choosing $c_{A}\left(\mu^{t}\right)$ and $z\left(\mu^{t}, y^{t-1}\right)$ to maximize

$$
\begin{aligned}
& \sum_{t=1}^{\infty} \beta^{t} \iint U\left(c_{A}\left(\mu^{t}\right)\right) z\left(\mu^{t}, y^{t-1}\right) g\left(\mu^{t}\right) f\left(y^{t-1}\right) d \mu^{t} d y^{t-1}+ \\
& \sum_{t=1}^{\infty} \beta^{t} \iint U\left(m\left(\mu^{t}, y^{t-1}\right)-a\left(\mu^{t}, y^{t-1}\right)\right)\left(1-z\left(\mu^{t}, y^{t-1}\right)\right) g\left(\mu^{t}\right) f\left(y^{t-1}\right) d \mu^{t} d y^{t-1}
\end{aligned}
$$

subject to the constraint

$$
\begin{gathered}
\bar{B} \geq \sum_{t=1}^{\infty} \iint Q\left(\mu^{t}\right)\left[N\left(\mu^{t}, y^{t-1}\right)-N\left(\mu^{t-1}, y^{t-2}\right)\right] f\left(y^{t-1}\right) d \mu^{t} d y^{t-1}+ \\
\sum_{t=1}^{\infty} \iint Q\left(\mu^{t}\right) P\left(\mu^{t}\right)\left[c_{A}\left(\mu^{t}\right)+\gamma-\left(m\left(\mu^{t}, y^{t-1}\right)-a\left(\mu^{t}, y^{t-1}\right)\right)\right] z\left(\mu^{t}, y^{t-1}\right) f\left(y^{t-1}\right) d \mu^{t} d y^{t-1} .
\end{gathered}
$$


Let $\eta$ denote the Lagrange multiplier on (29), and consider the following variational argument. For a state $\left(\mu^{t}, y^{t-1}\right)$, the increment to the Lagrangian of setting $z\left(\mu^{t}, y^{t-1}\right)=1$ is

$$
\begin{aligned}
& \beta^{t} U\left(c_{A}\left(\mu^{t}\right)\right) g\left(\mu^{t}\right) f\left(y^{t-1}\right)- \\
& \eta Q\left(\mu^{t}\right) P\left(\mu^{t}\right)\left[\left(c_{A}\left(\mu^{t}\right)+\gamma\right)-\left(m\left(\mu^{t}, y^{t-1}\right)-a\left(\mu^{t}, y^{t-1}\right)\right)\right] f\left(y^{t-1}\right)
\end{aligned}
$$

which is simply the direct utility gain $U\left(c_{A}\left(\mu^{t}\right)\right)$ minus the cost of the required transfers. The increment to the Lagrangian of setting $z\left(\mu^{t}, y^{t-1}\right)=0$ in this state is

$$
\beta^{t} U\left(\left(m\left(\mu^{t}, y^{t-1}\right)-a\left(\mu^{t}, y^{t-1}\right)\right)\right) g\left(\mu^{t}\right) f\left(y^{t-1}\right)
$$

which is simply the direct utility gain, since there are no transfers. The first-order condition with respect to $c_{A}$ is $\beta^{t} U^{\prime}\left(c_{A}\left(\mu^{t}\right)\right) g\left(\mu^{t}\right)=\eta Q\left(\mu^{t}\right) P\left(\mu^{t}\right)$. Subtracting (31) from (30) and using the first-order condition when $z=1$ gives the cutoff rules defined by (8). More formally, we have

LEMMA 2. Given active households' consumption $c_{A}\left(\mu^{t}\right)$, a household chooses $z\left(\mu^{t}, y^{t-1}\right)=0$ if $m\left(\mu^{t}, y^{t-1}\right)-a\left(\mu^{t}, y^{t-1}\right) \in\left(\frac{y_{L}\left(c_{A}\left(\mu^{t}\right), \mu_{t}\right)}{\mu_{t}}, \frac{y_{H}\left(c_{A}\left(\mu^{t}\right), \mu_{t}\right)}{\mu_{t}}\right)$ and $z\left(\mu^{t}, y^{t-1}\right)=1$ otherwise.

These lemmas complete the proof of Proposition 1. To complete our asset pricing formulas, we need to compute the equilibrium value of the multiplier $\lambda$. Given the equilibrium values of consumption computed in Proposition 1, we have that $\lambda$ solves

$$
\sum_{t=1}^{\infty} \int \beta^{t} U^{\prime}\left(c_{A}\left(\mu_{t}\right)\right) \int_{y_{L}\left(\mu_{t}\right)}^{y_{H}\left(\mu_{t}\right)} \frac{M\left(\mu^{t}\right)}{Y}\left[c_{T}\left(\mu_{t}\right)+\gamma-\frac{y}{\mu_{t}}\right] f(y) d y g\left(\mu^{t}\right) d \mu^{t}=\frac{\bar{B}}{\lambda} .
$$

Households will not want to store cash in the asset market if nominal interest rates are positive. Thus, to ensure that $N=0$, we need only check that nominal interest rates are always positive. We now turn to the problem of developing conditions sufficient to ensure that households never want to store cash in the goods market.

Assume that households have constant relative risk aversion utility of the form $U(c)=$ $c^{1-\sigma} /(1-\sigma)$. Let $Q\left(\mu^{t}\right)$ and $P\left(\mu^{t}\right)$ be the prices constructed above when $a$ and $N$ are assumed equal to zero.

Consider first the consumption of a household that deviates from the strategy of never holding cash from one period to the next in the goods market. From Lemmas 1 and 2, we have that, with a fixed plan $\left\{a_{t}\left(\mu^{t}, y^{t-1}\right)\right\}$ for holding cash in the goods market, this deviant household's consumption choices are similar to those of a household that does not hold cash in 
the goods market. In particular, in those states of nature in which the deviant chooses to pay the fixed cost to trade, from Lemma 1, the household's consumption satisfies the first-order condition $\beta^{t} U^{\prime}\left(c_{A}^{d}\left(\mu^{t}\right)\right) g\left(\mu^{t}\right)=\eta^{d} Q\left(\mu^{t}\right) P\left(\mu^{t}\right)$, where $\eta^{d}$ is the Lagrange multiplier on this household's period 0 budget constraint. Thus, in those states in which the deviant household pays the fixed cost to trade, it equates its marginal rate of substitution to that of other active households that do not deviate. Given constant risk aversion, this implies that $c_{A}^{d}\left(\mu^{t}\right)=\theta c_{A}\left(\mu_{t}\right)$ for all $\mu^{t}$ for some fixed factor of proportionality $\theta$. In those states of nature in which the deviant household does not choose to pay the fixed cost, its consumption is $c^{d}\left(\mu^{t}, y^{t-1}\right)=m^{d}\left(\mu^{t}, y^{t-1}\right)-a^{d}\left(\mu^{t}, y^{t-1}\right)$, and its decision whether to pay the fixed cost is determined by the cutoffs $y_{L}\left(\theta c_{T}\left(\mu_{t}\right), \mu_{t}\right)$ and $y_{H}\left(\theta c_{T}\left(\mu_{t}\right), \mu_{t}\right)$ described in Lemma 2. Since $m^{d}\left(\mu^{t}, y^{t-1}\right)=\left[y_{t-1}+a^{d}\left(\mu^{t-1}, y^{t-2}\right)\right] / \mu_{t}$ and, in the event that the deviant household pays the fixed cost, $x^{d}\left(\mu^{t}, y^{t-1}\right)=\theta c_{T}\left(\mu_{t}\right)-\left[m_{t}^{d}\left(\mu^{t}, y^{t-1}\right)-a^{d}\left(\mu^{t}, y^{t-1}\right)\right]$, the factor of proportionality $\theta$ (and the implied Lagrange multiplier $\eta^{d}$ ) that corresponds to any fixed plan $\left\{a_{t}\left(\mu^{t}, y^{t-1}\right)\right\}$ for holding cash in the goods market must be set so that the deviant household's period 0 budget constraint holds with equality. The relevant budget constraint is, then, written as

$$
\bar{B}=\sum_{t=1}^{\infty} \iint Q\left(\mu^{t}\right) P\left(\mu^{t}\right)\left[\theta c_{T}\left(\mu_{t}\right)+\gamma-\left(m\left(\mu^{t}, y^{t-1}\right)-a\left(\mu^{t}, y^{t-1}\right)\right)\right] z\left(\mu^{t}, y^{t-1}\right) f\left(y^{t-1}\right) d \mu^{t} d y^{t-1}
$$

where $z\left(\mu^{t}, y_{t-1}\right)=1$ if $\left\{\left[y_{t-1}+a^{d}\left(\mu^{t-1}, y^{t-2}\right)\right] / \mu_{t}\right\}-a^{d}\left(\mu^{t}, y^{t-1}\right)$ is in the interval $\left[y_{L}\left(\theta c_{T}\left(\mu_{t}\right), \mu_{t}\right) / \mu_{t}, y_{H}\left(\theta c_{T}\left(\mu_{t}\right), \mu_{t}\right) / \mu_{t}\right]$ and $z\left(\mu^{t}, y_{t-1}\right)=0$ otherwise.

Next observe that, since the cutoffs $y_{L}\left(\theta c_{T}\left(\mu_{t}\right), \mu_{t}\right)$ and $y_{H}\left(\theta c_{T}\left(\mu_{t}\right), \mu_{t}\right)$ are monotonically increasing in $\theta$ for all values of $\mu_{t}$, no deviant household would choose a plan $\left\{a_{t}\left(\mu^{t}, y^{t-1}\right)\right\}$ for holding cash in the goods market such that the implied factor of proportionality $\theta$ was so small that $y_{H}\left(\theta c_{T}\left(\mu_{t}\right), \mu_{t}\right) \leq y_{L}\left(c_{T}\left(\mu_{t}\right), \mu_{t}\right)$ for all possible realizations of $\mu_{t}$. To see this, observe that the consumption of such a deviant household would lie below the consumption we have constructed for a household that never holds cash in the goods market in every possible state of nature $\mu^{t}, y^{t-1}$. Thus, the utility of such a deviant household would have to be lower than that of a household that never held cash in the goods market. Let $\bar{\theta}=\sup \left\{\theta \mid y_{H}\left(\theta_{c_{T}}\left(\mu_{t}\right), \mu_{t}\right) \leq y_{L}\left(c_{T}\left(\mu_{t}\right), \mu_{t}\right)\right\}$.

LEMMA 3. It is optimal for a household to never hold over cash in the goods market if, for all $a \geq 0, \mu_{t}$ and $\theta \geq \bar{\theta}$

$$
\begin{aligned}
& U^{\prime}\left(\frac{y_{H}\left(\theta c_{A}\left(\mu_{t}\right), \mu_{t}\right)}{\mu_{t}}\right)>\beta \int_{\mu_{t+1}} \int_{y_{L}\left(\theta c_{A}\left(\mu_{t+1}\right), \mu_{t+1}\right)-a}^{y_{H}\left(\theta c_{A}\left(\mu_{t+1}\right), \mu_{t+1}\right)-a} U^{\prime}\left(\frac{y_{t}+a}{\mu_{t+1}}\right) \frac{f\left(y_{t}\right)}{\mu_{t+1}} g\left(\mu_{t+1} \mid \mu^{t}\right) d y_{t} d \mu_{t+1}+ \\
& \beta \int_{\mu_{t+1}} \frac{U^{\prime}\left(\theta c_{A}\left(\mu_{t+1}\right)\right)}{\mu_{t+1}}\left[F\left(y_{L}\left(\theta c_{A}\left(\mu_{t+1}\right), \mu_{t+1}\right)-a\right)+1-F\left(y_{H}\left(\theta c_{A}\left(\mu_{t+1}\right), \mu_{t+1}\right)-a\right)\right] g\left(\mu_{t+1} \mid \mu^{t}\right) d \mu_{t+1} .
\end{aligned}
$$


Proof. Given any plan $\left\{a_{t}\left(\mu^{t}, y^{t-1}\right)\right\}$ for holding cash in the goods market and an associated value of $\theta$, the highest consumption that a deviant household could have in period $t$ is $y_{H}\left(\theta c_{T}\left(\mu_{t}\right), \mu_{t}\right) / \mu_{t}$, and thus, $U^{\prime}\left(y_{H}\left(\theta c_{T}\left(\mu_{t}\right), \mu_{t}\right) / \mu_{t}\right)$ is the smallest marginal utility of consumption it could have in that period.The terms on the right side of the condition in the lemma are the expected value of the product of the marginal utility of consumption and the return to holding currency in the goods market $\left(1 / \mu_{t+1}\right)$ in period $t+1$. Thus, the condition in the lemma ensures that such a household always prefers to consume its real balances in period $t$ rather than carry them over into period $t+1$ at a rate of return $1 / \mu_{t+1}$. Therefore, this condition implies that no plan for holding cash in the goods market gives higher utility than the plan of never holding cash in the goods market.

\section{Appendix B}

In this appendix, we solve for $\phi$ when the endowment $y$ is $\log$-normal, with $\log y$ having a normal distribution with mean zero and variance $\sigma_{y}^{2}$. The resource constraint is

$$
\begin{aligned}
& \left(c_{A}+\gamma\right)\left[F\left(\log y_{L}, ; 0, \sigma_{y}\right)+1-F\left(\log y_{H} ; 0, \sigma_{y}\right)\right]+ \\
& \frac{1}{\bar{\mu}} \frac{1}{\sigma_{y} \sqrt{2 \pi}} \int_{\log y_{L}}^{\log y_{H}} \exp (w) \exp \left(-\frac{1}{2}\left(\frac{w}{\sigma_{y}}\right)^{2}\right) d w=\exp \left(\frac{\sigma_{y}^{2}}{2}\right),
\end{aligned}
$$

where $F\left(\log y_{L}, ; 0, \sigma_{y}\right)$ is the cumulative distribution function (cdf) of a normal mean zero standard deviation $\sigma_{y}$ evaluated at $\log y_{L}$. We can compute the integral of the resource constraint as follows:

$$
\begin{aligned}
& \frac{1}{\bar{\mu}} \frac{1}{\sigma_{y} \sqrt{2 \pi}} \int_{\log y_{L}}^{\log y_{H}} \exp (w) \exp \left(-\frac{1}{2}\left(\frac{w}{\sigma_{y}}\right)^{2}\right) d w= \\
& \frac{1}{\bar{\mu}} \exp \left(\frac{\sigma_{y}^{2}}{2}\right) \frac{1}{\sigma_{y} \sqrt{2 \pi}} \int_{\log y_{L}}^{\log y_{H}} \exp \left(-\frac{1}{2}\left(\frac{w-\sigma_{y}^{2}}{\sigma_{y}}\right)^{2}\right) d w
\end{aligned}
$$

Now (33) is the integral of the density of a normal distribution with mean $\sigma_{y}^{2}$ and variance $\sigma_{y}^{2}$. Thus, the resource constraint can be written as

$$
\begin{aligned}
& \left(c_{A}+\gamma\right)\left[F\left(\log y_{L}, ; 0, \sigma_{y}\right)+1-F\left(\log y_{H} ; 0, \sigma_{y}\right)\right]+ \\
& \frac{1}{\bar{\mu}} \exp \left(\frac{\sigma_{y}^{2}}{2}\right)\left[F\left(\log y_{H} ; \sigma_{y}^{2}, \sigma_{y}\right)-F\left(\log y_{L} ; \sigma_{y}^{2}, \sigma_{y}\right)\right]=\exp \left(\frac{\sigma_{y}^{2}}{2}\right) .
\end{aligned}
$$

Given $\mu$, the equilibrium values of $c_{T}, y_{L}$, and $y_{H}$ are found as the solution to the equations (5) and (7). We solve these equations numerically for $\sigma=2, \gamma=.005, \sigma_{y}=.03$, and $\bar{\mu}=1.03^{25}$, so that annualized inflation is 3 percent. With these parameters $\phi=2.14$. 


\section{References}

Aiyagari, S. Rao, and Gertler, Mark. "Asset Returns With Transactions Costs and Uninsured Individual Risk." J. Monetary Econ. 27 (June 1991): 311-31.

Allen, Franklin, and Gale, Douglas. "Limited Market Participation and Volatility of Asset Prices." A.E.R. 84 (September 1994): 933-55.

Alvarez, Fernando, and Atkeson, Andrew. "Money and Exchange Rates in the Grossman-WeissRotemberg Model." J. Monetary Econ. 40 (December 1997): 619-40.

Balasko, Yves; Cass, David; and Shell, Karl. "Market Participation and Sunspot Equilibria." Rev. Econ. Studies 62 (July 1995): 491-512.

Barr, David G., and Campbell, John Y. "Inflation, Real Interest Rates, and the Bond Market: A Study of UK Nominal and Index-Linked Government Bond Prices." J. Monetary Econ. 39 (August 1997): 361-83.

Basak, Suleyman, and Cuoco, Domenico. "An Equilibrium Model With Restricted Stock Market Participation." Rev. Financial Studies 11 (Summer 1998): 309-41.

Baumol, William J. "The Transactions Demand for Cash: An Inventory Theoretic Approach." Q.J.E. 66 (November 1952): 545-56.

Campbell, John Y., and Ammer, John. "What Moves the Stock and Bond Markets? A Variance Decomposition for Long-Term Asset Returns." J. Finance 48 (March 1993): 3-37.

Campbell, John Y.; Lo, Andrew W.; and MacKinlay, A. Craig. The Econometrics of Financial Markets. Princeton, N. J.: Princeton University Press, 1997.

Chari, V.V.; Christiano, Lawrence J.; and Eichenbaum, Martin. "Inside Money, Outside Money, and Short-Term Interest Rates." J. Money, Credit, and Banking 27 (Part 2, November 1995): 1354-86.

Chari, V.V.; Kehoe, Patrick J.; and McGrattan, Ellen R. "Can Sticky Price Models Generate Volatile and Persistent Real Exchange Rates?" Research Department Staff Report 223. Minneapolis, Minn.: Federal Reserve Bank of Minneapolis, December 1998.

Chatterjee, Satyajit, and Corbae, Dean. "Endogenous Market Participation and the General Equilibrium Value of Money." J.P.E. 100 (June 1992): 615-46.

Christiano, Lawrence J., and Eichenbaum, Martin. "Liquidity Effects and the Monetary Transmission Mechanism." A.E.R. 82 (May 1992): 346-53.

"Liquidity Effects, Monetary Policy, and the Business Cycle." J. Money, Credit, and 
Banking 27 (Part 1, November 1995): 1113-36.

Christiano, Lawrence J.; Eichenbaum, Martin; and Evans, Charles L. "Modeling Money." Working Paper 6371. Cambridge, Mass.: National Bureau of Economic Research, January 1998.

Cochrane, John H. "Shocks." Carnegie-Rochester Conf. Ser. Public Policy 41 (December 1994): 295-364.

"What Do the VARs Mean? Measuring the Output Effects of Monetary Policy." J. Monetary Econ. 41 (April 1998): 277-300.

Cuny, Charles J. "The Role of Liquidity in Futures Market Innovations." Rev. Financial Studies 6 (Spring 1993): 57-78.

Dotsey, Michael, and Ireland, Peter. "Liquidity Effects and Transactions Technologies." J. Money, Credit, and Banking 27 (Part 2, November 1995): 1440-57.

Evans, Charles L., and Marshall, David A. "Monetary Policy and the Term Structure of Nominal Interest Rates: Evidence and Theory." Carnegie-Rochester Conf. Ser. Public Policy 49 (December 1998): 53-111.

Friedman, Milton. "The Role of Monetary Policy." A.E.R. 58 (March 1968): 1-17.

Fuerst, Timothy S. "Liquidity, Loanable Funds, and Real Activity." J. Monetary Econ. 29 (February 1992): 3-24.

Grilli, Vittorio, and Roubini, Nouriel. "Liquidity and Exchange Rates." J. International Econ. 32 (May 1992): 339-52.

Grossman, Sanford J. "Monetary Dynamics With Proportional Transaction Costs and Fixed Payment Periods." In New Approaches to Monetary Economics: Proceedings of the Second International Symposium in Economic Theory and Econometrics, edited by William A. Barnett and Kenneth J. Singleton. Cambridge, U.K.: Cambridge University Press, 1987.

Grossman, Sanford, and Weiss, Laurence. "A Transactions-Based Model of the Monetary Transmission Mechanism." A.E.R. 73 (December 1983): 871-80.

Hirshleifer, David. "Residual Risk, Trading Costs, and Commodity Futures Risk Premia." Rev. Financial Studies 1 (Summer 1988): 173-93.

Jovanovic, Boyan. "Inflation and Welfare in the Steady State." J.P.E. 90 (June 1982): 561-77.

Lucas, Robert E., Jr. "Asset Prices in an Exchange Economy." Econometrica 46 (November 1978): $1429-45$.

. "Interest Rates and Currency Prices in a Two-Country World." J. Monetary Econ. 
10 (November 1982): 335-60.

. "Money in a Theory of Finance." Carnegie-Rochester Conf. Ser. Public Policy 21 (Autumn 1984): 9-45.

. "Liquidity and Interest Rates." J. Econ. Theory 50 (April 1990): 237-64.

Merton, Robert C. "A Simple Model of Capital Market Equilibrium With Incomplete Information." J. Finance 42 (July 1987): 483-510.

Mussa, Michael. "Nominal Exchange Rate Regimes and the Behavior of Real Exchange Rates: Evidence and Implications." Carnegie-Rochester Conf. Ser. Public Policy 25 (Autumn 1986): $117-213$.

Obstfeld, Maurice, and Rogoff, Kenneth. "Exchange Rate Dynamics Redux." J.P.E. 103 (June 1995): $624-60$.

Pennacchi, George G. "Identifying the Dynamics of Real Interest Rates and Inflation: Evidence Using Survey Data." Rev. Financial Studies 4 (1991): 53-86.

Romer, David. "A Simple General Equilibrium Version of the Baumol-Tobin Model." Q.J.E. 101 (November 1986): 663-85.

Rotemberg, Julio J. "A Monetary Equilibrium Model With Transactions Costs." J.P.E. 92 (February 1984): 40-58.

"Money and the Terms of Trade." J. International Econ. 19 (August 1985): 141-60.

Saito, Makoto. "Limited Participation and Asset Pricing." Manuscript. Vancouver, B.C., Canada: University of British Columbia, 1996.

Schlagenhauf, Don E., and Wrase, Jeffrey M. "Liquidity and Real Activity in a Simple Open Economy Model." J. Monetary Econ. 35 (August 1995a): 431-61.

. "Liquidity Effects and Transactions Technologies: Comment." J. Money, Credit, and Banking 27 (Part 1, November 1995b): 1461-71.

Tobin, James. "The Interest-Elasticity of Transactions Demand for Cash." Rev. Econ. and Statis. 38 (August 1956): 241-47.

Vasicek, Oldrich. "An Equilibrium Characterization of the Term Structure." J. Financial Econ. 5 (November 1977): 177-88. 
Table 1

\section{Exchange Rates in Low Inflation Countries}

Quarterly, 1970:1-1999:3

\begin{tabular}{lcccc}
\hline & $\begin{array}{c}\text { Mean Inflation } \\
\text { (based on a consumer } \\
\text { price index) }\end{array}$ & $\begin{array}{c}\text { Nominal/Real } \\
\text { Volatility }\end{array}$ & $\begin{array}{c}\text { Fominal, Real } \\
\text { Correlation }\end{array}$ & $\begin{array}{c}\text { Persistence: } \\
\text { Real Serial } \\
\text { Correlation }\end{array}$ \\
\cline { 2 - 5 } Canada & 5.2 & .96 & .93 & .79 \\
France & 5.9 & 1.06 & .99 & .78 \\
Germany & 3.4 & 1.01 & .98 & .76 \\
Italy & 9.0 & 1.10 & .98 & .79 \\
Japan & 4.0 & 1.00 & .98 & .79 \\
United Kingdom & 7.5 & 1.06 & .97 & .78 \\
\hline
\end{tabular}

SOURCE. - International Monetary Fund 


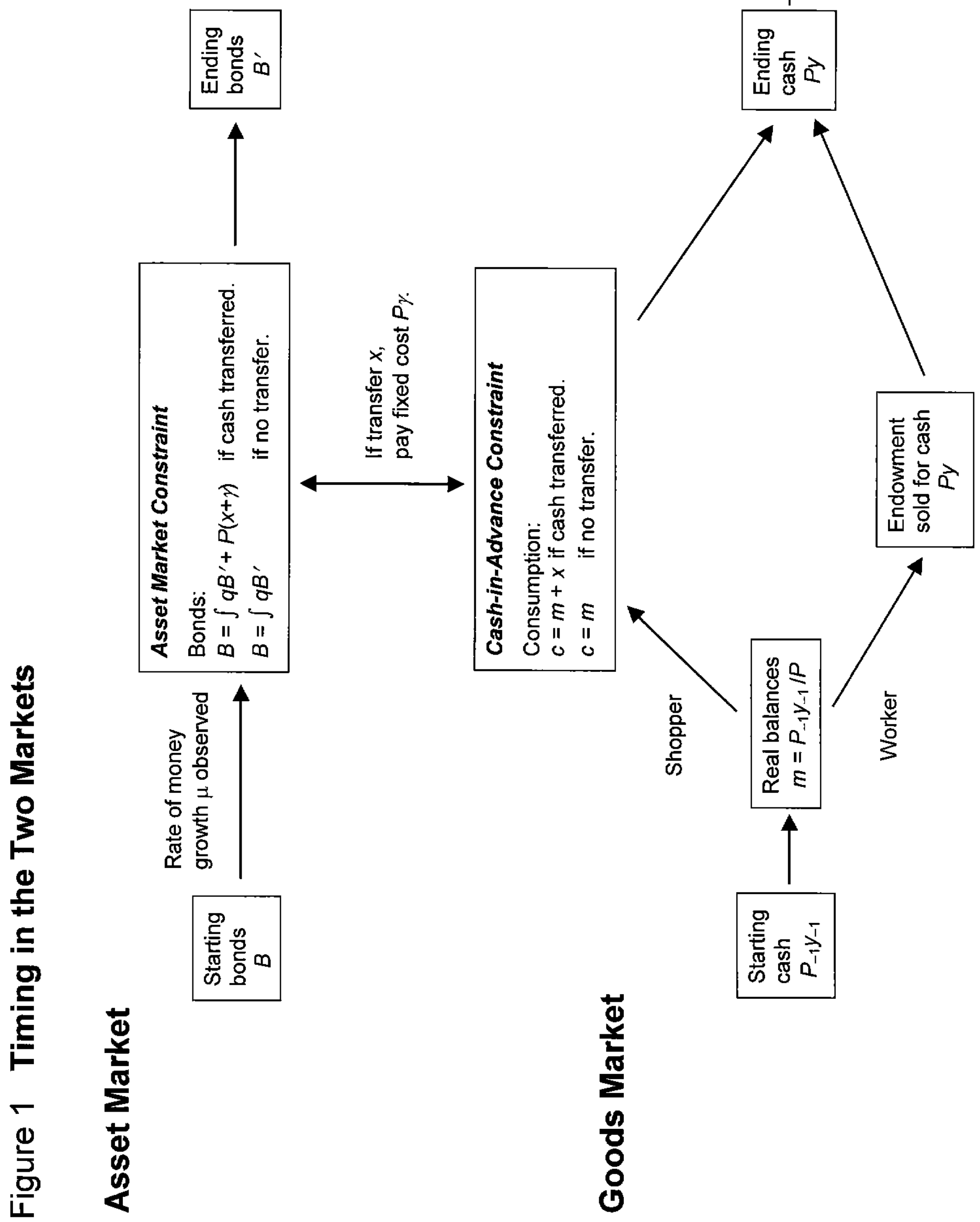




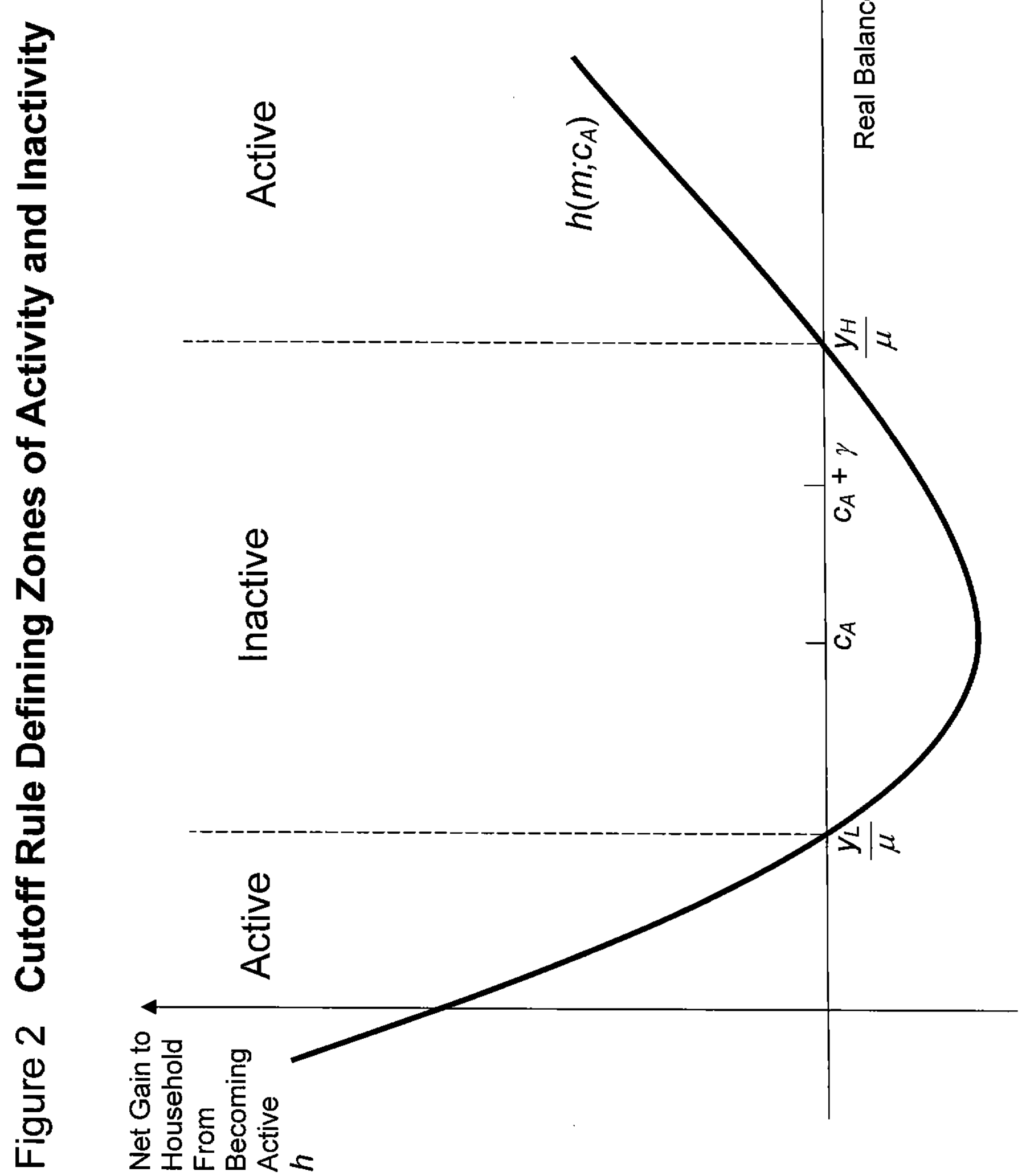




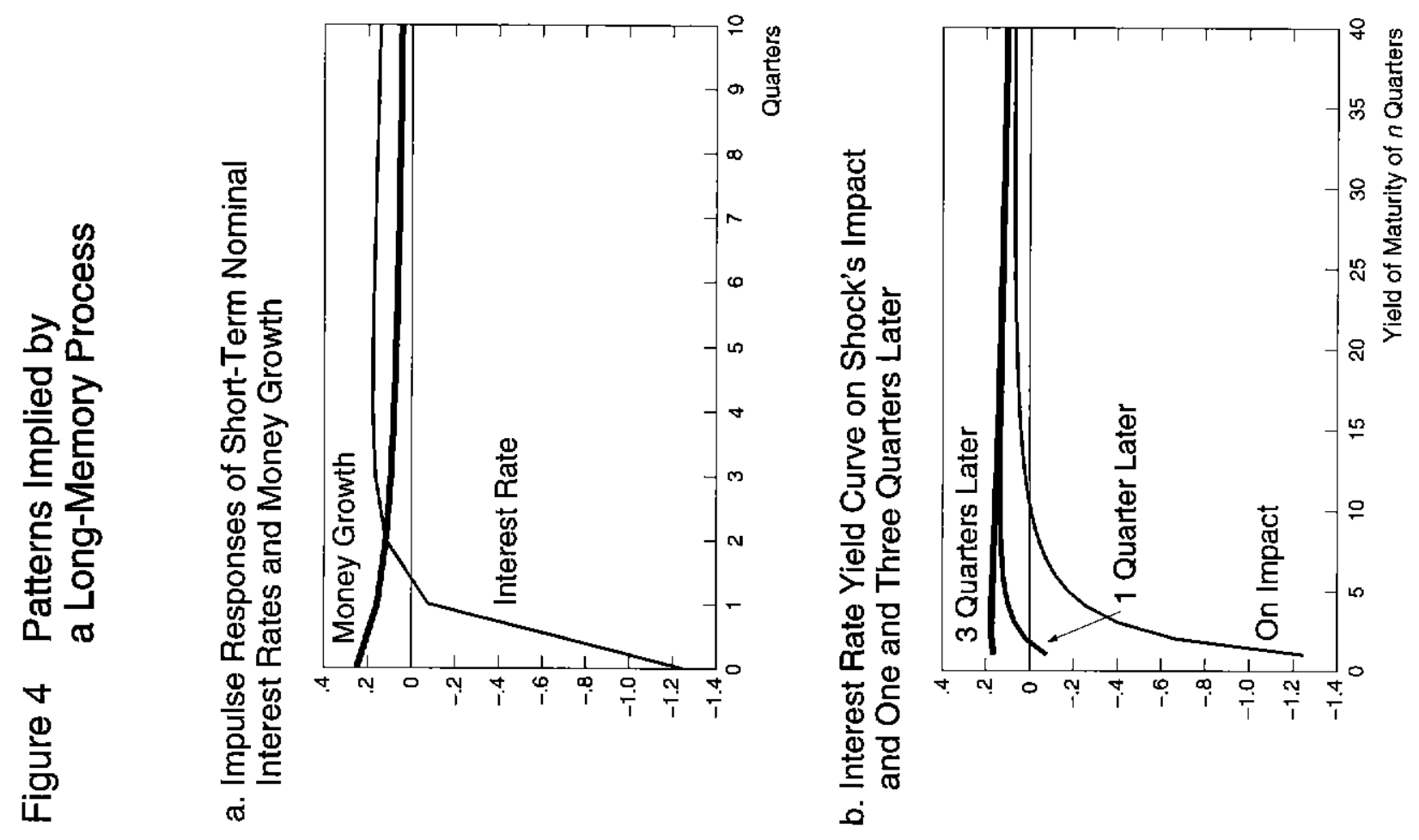

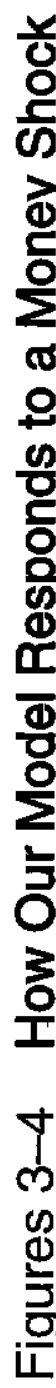
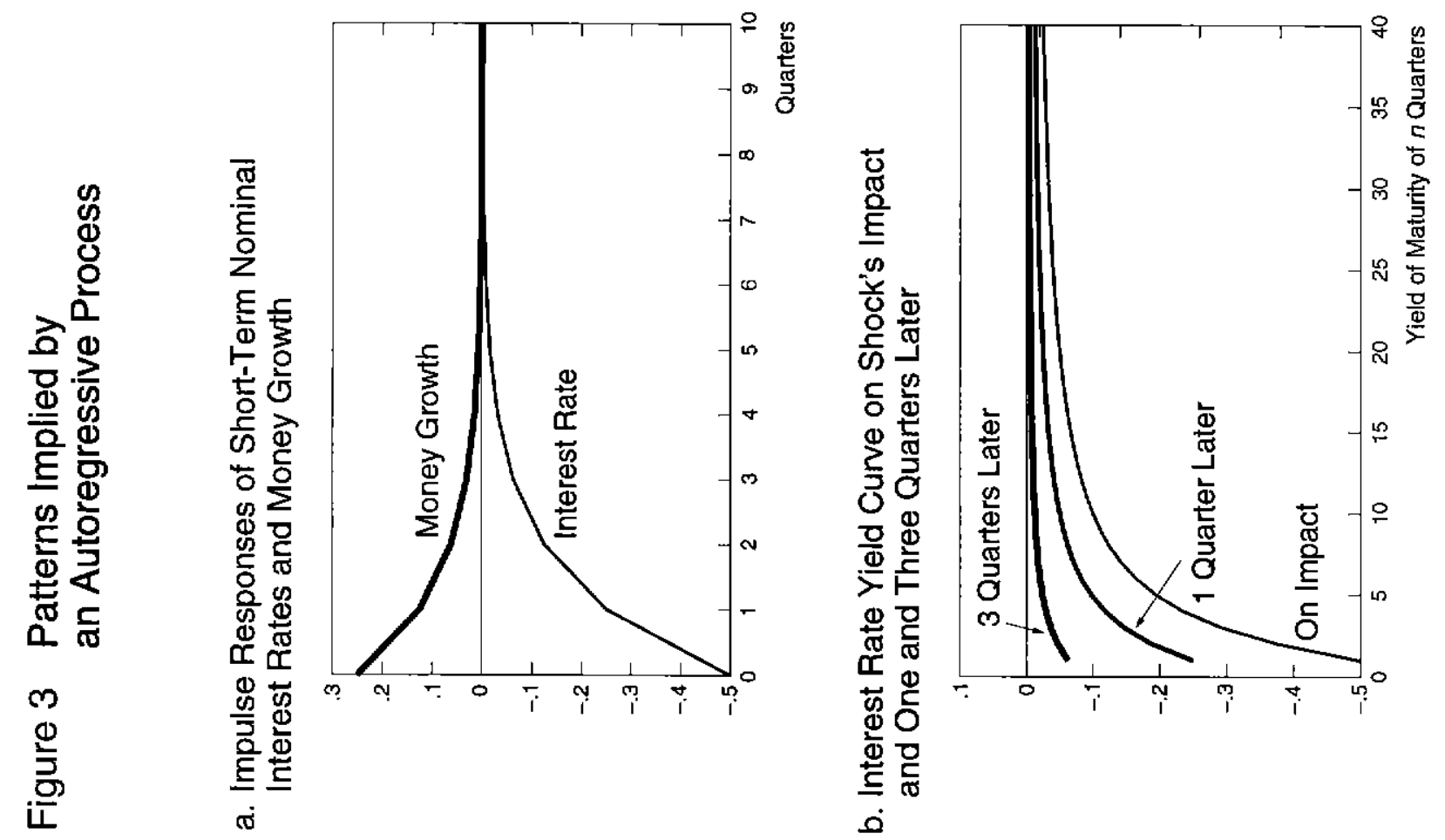
Figure 5

The Model's Exchange Rate Statistics vs. The Segmentation Parameter

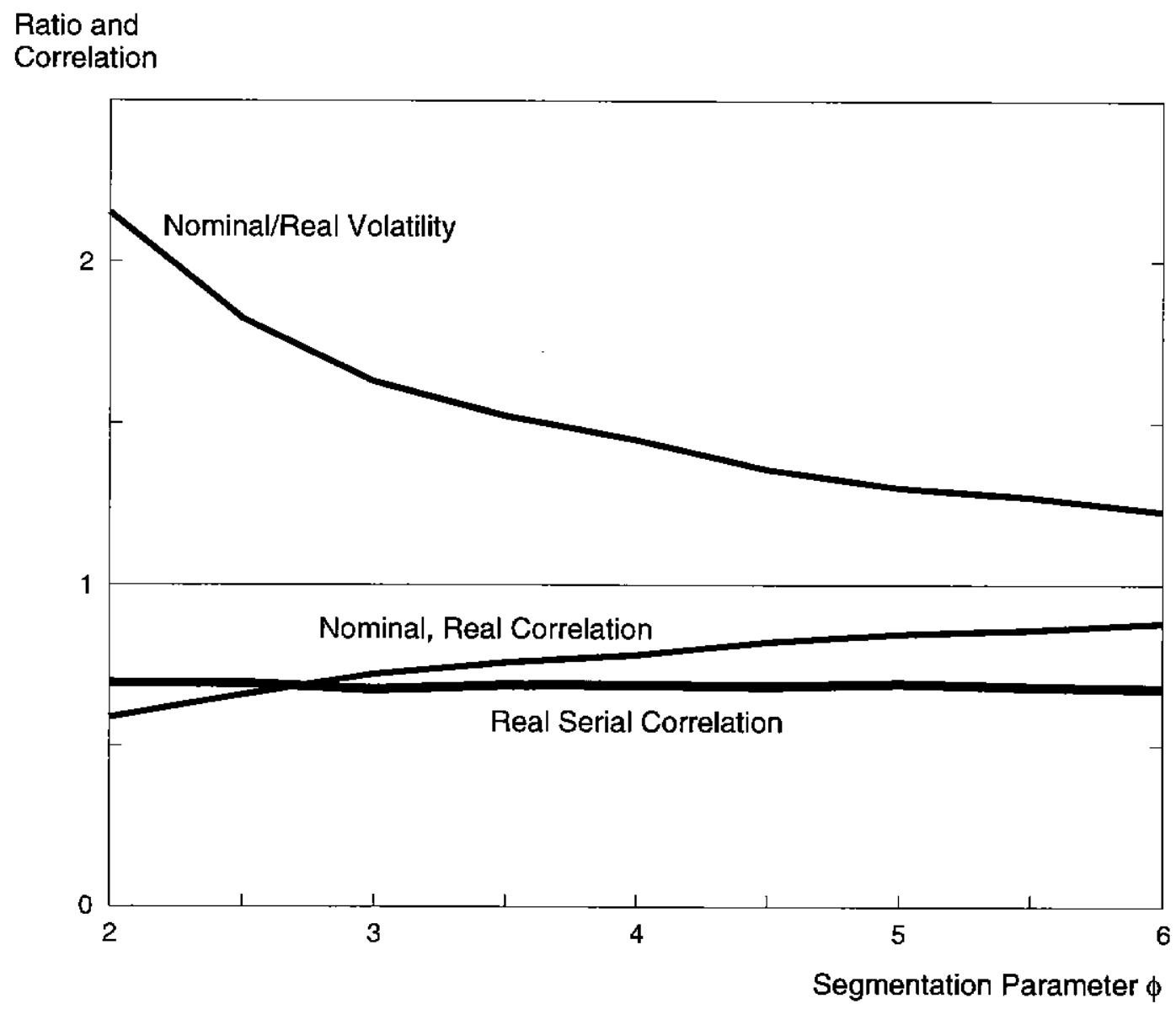


Figure 6

Relative Volatility of Nominal and Real

Exchange Rates vs. Inflation

Ratio of Standard Deviations of Nominal and Real Exchange Rates

vs. Mean of Log of Consumer Price Index Changes

in 41 Selected Countries, 1970:1-1999:3

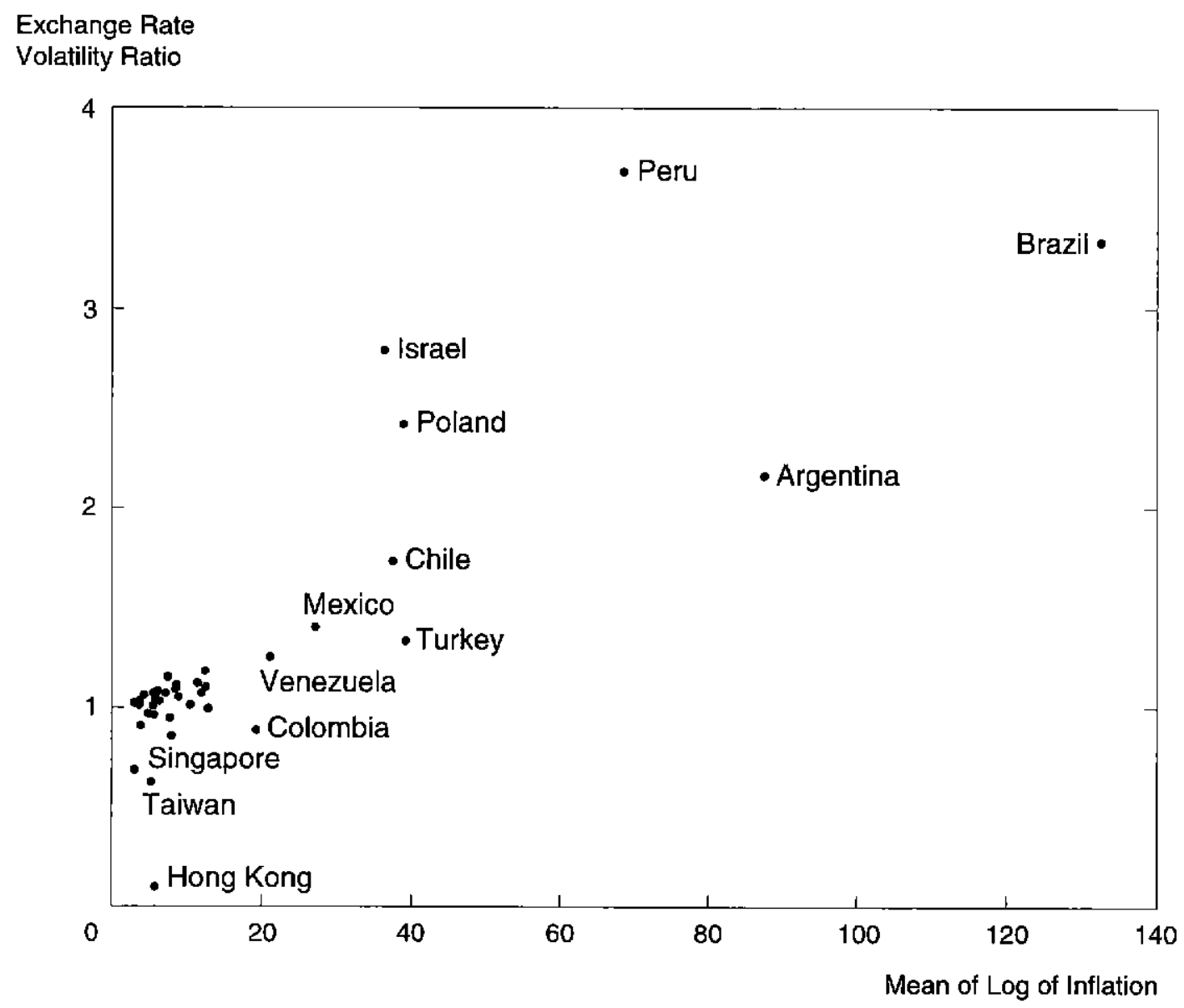

Note: The cluster of countries with low relative volatility of nominal and real exchange rates and low inflation includes Australia, Austria, Belgium, Canada, Denmark, Finland, France, Germany, Greece, Hungary, India, Indonesia, Ireland, Italy, Japan, Korea, Malaysia, the Netherlands, New Zealand, Norway, the Philippines, Portugal, South Africa, Spain, Sweden, Switzerland, Thailand, and the United Kingdom.

Source: International Monetary Fund (International Financial Statistics) 